\title{
Iterative uncertainty reduction in multi-actor smart service innovation
}

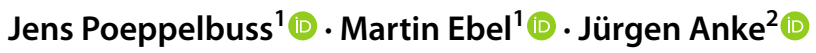

Received: 22 October 2020 / Accepted: 13 September 2021 / Published online: 2 December 2021

(c) The Author(s) 2021, corrected publication 2022

\begin{abstract}
Smart service innovation is the process of reconfiguring resources, structures, and value co-creation processes in service systems that result in novel data-driven service offerings. The nature of such offerings requires the involvement of multiple actors, which has been investigated by a few studies only. In particular, little is known about the multiple actors' efforts to manage uncertainty in the process of establishing smart service systems. Empirically grounded in data from 25 interviews with industry experts, we explore how organizations act and interact in smart service innovation processes. For our data analysis, we adopt a microfoundational view to derive a theoretical model that conceptualizes actor engagement as a microfoundation for iterative uncertainty reduction in the actor-to-actor network of the smart service system. Our study contributes to information systems research on service systems engineering and digital transformation by explaining smart service innovation from both a multi-actor and a multi-level perspective, drawing on service-dominant (S-D) logic and microfoundations as well-established theoretical lenses.
\end{abstract}

Keywords Service system $\cdot$ Digital transformation $\cdot$ Microfoundations $\cdot$ S-D logic $\cdot$ Actor engagement

JEL classification $\mathrm{M} 15 \cdot \mathrm{L} 86 \cdot \mathrm{M} 15 \cdot \mathrm{O} 32 \cdot \mathrm{O} 30$

\section{Introduction}

Smart service innovation can be a part of digital innovation and transformation initiatives that organizations pursue to strengthen their competitive positions (Klos et al., 2021; Vial, 2019; Wessel et al., 2020; Wiesböck \& Hess, 2020). They appropriate digital technologies such as the Internet of Things (IoT), big data, artificial intelligence (AI), and cloud computing as enablers for changing service systems into smart service systems (Beverungen et al., 2019b; Parida et al., 2019; Sjödin et al., 2020a; Vial, 2019). Smart service systems connect things and people, collect and process data, are capable of independent

Responsible Editor: Thomas Hess

Jens Poeppelbuss

jens.poeppelbuss@isse.rub.de

1 Ruhr-Universität Bochum, Universitätsstraße 150, 44801 Bochum, Germany

2 HTW Dresden, Friedrich-List-Platz 1, 01069 Dresden, Germany learning, adaptation, and decision making, and thereby automate and facilitate value co-creation in actor-to-actor networks (Beverungen et al., 2019a; Maglio \& Lim, 2018; National Science Foundation, 2014). Smart service innovation denotes the process of changing the resource configurations, structures, and value co-creation processes of smart service systems (Anke et al., 2020c; Breidbach \& Maglio, 2015; Edvardsson \& Tronvoll, 2013; Vargo et al., 2010).

We can observe examples of smart service innovation in various contexts. In consumer markets, car manufacturers connect vehicles with digital platforms to analyze driving behavior based on sensor data, schedule workshop appointments, provide usage-based insurance, or give feedback on driving behavior (Beverungen et al., 2019a; Husnjak et al., 2015). In industrial contexts, manufacturing firms innovate by combining digitally connected machines and equipment with value propositions like condition monitoring, predictive maintenance, remote service and control, and fleet management (Herterich et al., 2015). In both consumer and industrial contexts, a change in value propositions can go hand in hand with a change in value capture when revenue models divert from transactional product and service sales towards more relational and long-term approaches such as subscriptions, pay-per-use, and performance-based contracting 
(Coreynen et al., 2017; Paiola \& Gebauer, 2020; Weking et al., 2020). Statistical data underpins the economic relevance of smart service innovation. Germany, for instance, envisions a productivity increase of more than 30 percent by 2025 compared to 2015 by connecting machines, systems, and factories to the Internet and thereby forming a so-called "Smart Service World" (acatech, 2015). The market volume for vehicle-based connected services in the USA and Europe is expected to rise from USD 4.7 billion and USD 2.5 billion in 2020 to around USD 22 billion and USD 14 billion respectively by 2030 (PwC, 2019).

Smart service innovation has become a central theme of information systems research over the last years (Beverungen et al., 2019a; Yang et al., 2021) with links to many other disciplines including services marketing (Paluch \& Tuzovic, 2019; Wünderlich et al., 2013, 2015), industrial marketing management (Sjödin et al., 2020b; Sklyar et al., 2019), innovation management (Maglio \& Lim, 2016), and industrial engineering (Rabe et al., 2018), amongst others. The information systems discipline is considered to be particularly suitable to study the systematic development of smart service systems due to its interdisciplinary nature (Böhmann et al., 2014). In this context, the term service systems engineering (SSE) is used to emphasize "a departure from traditional service engineering research" (Böhmann et al., 2014, p. 74) "towards systemic, interactive and collaborative service innovation based on advances in IT" (Böhmann et al., 2014, p. 74) that adopts the ideas of service systems (Beverungen et al., 2018; Maglio et al., 2009) and service ecosystems (Vargo \& Lusch, 2016, 2017; Vink et al., 2021). Following this line of thought, Höckmayr and Roth (2017) formulate requirements for SSE methods that include, amongst others, the imperative to "address larger constellations within which multiple actors become joined over time and space" and to "acknowledge the role of knowledge and skills applied by various actors" in service innovation (Höckmayr \& Roth, 2017, p. 5). Referring to digital transformation more broadly, Alt (2019) similarly calls for methodologies that cover an ecosystem-wide perspective that integrate aspects of business and technological change.

Applying an ecosystem's perspective is meaningful as smart service innovation requires the involvement of multiple actors (Anke et al., 2020c; Ekman et al., 2016; Schymanietz \& Jonas, 2020; Vink et al., 2021). Organizations need to collaborate across their boundaries as the components of a smart service system are usually designed to "operate and interact with the solutions offered by many other manufacturers, used by customers, delivered by distributors, maintained by different service partners, and operated by third parties" (Kohtamäki et al., 2019, p. 381). Collaborative smart service innovation can affect the engagement of an organization with its customers fundamentally (Abrell et al., 2016; Chowdhury et al., 2018; Jussen et al., 2019; Storbacka et al., 2016), e.g., by involving them as co-designers (Jonas et al., 2018; Martinez et al., 2010). The infusion of advanced and complex digital technologies in smart service systems is likely to require partner organizations who are specialists in systems integration, user experience design, cloud computing, data analytics, or platform business, all of which are usually not available within the same organization (Anke et al., 2020c; Djellal \& Gallouj, 2018; Sklyar et al., 2019). Finally, external facilitators can help to guide actors through smart service innovation processes, e.g., by establishing innovation processes, organizing workshops, and managing innovation projects (Anke et al., 2020c; Schymanietz \& Jonas, 2020). Academia has just begun to investigate smart service innovation from such a multi-actor perspective that goes beyond the single focal organization or the dyadic perspective of a provider and a customer actor, e.g., by identifying the roles of diverse actors in smart service innovation processes (Anke et al., 2020c; Ekman et al., 2016; Ostrom et al., 2015; Schymanietz \& Jonas, 2020; Vink et al., 2021).

Multi-actor smart service innovation is beset with uncertainty as it happens in "fast-changing real-world environments" (Grotherr et al., 2018, p. 3). Uncertainty means that the multiple actors involved may not have the necessary understanding to make decisions as future states of the smart service system may be highly variable or unpredictable (Ramirez Hernandez \& Kreye, 2021). The innovation process can be affected by different types of uncertainty (Ramirez Hernandez \& Kreye, 2021). For instance, environmental uncertainty can lead organizations into both service and digitalization paradoxes, when substantial investments in extending the digital service business fail to deliver greater profits because of spiraling cost increases and a lack of customer understanding or willingness to pay (Gebauer et al., 2005; Sjödin et al., 2020b; Wolf et al., 2020). Relational uncertainty can result in ambiguity, opportunism, or conformity issues due to the unpredictable behavior of collaborating actors (Ramirez Hernandez \& Kreye, 2021). In their recent study, Sjödin et al. (2020b) find that organizations employ iterative and agile ways of working to deal with complexity and reduce uncertainty. They explicitly call for future research that takes a multi-actor perspective as broader sets of ecosystem actors shape value creation in times of digital transformation (Sjödin et al., 2020b).

This qualitative-empirical interview study intends to uncover and explain how the activities of the broader set of actors engaged in smart service innovation relate to uncertainty reduction in the overall smart service system. We approach this relationship through the theoretical lens of microfoundations (Foss, 2016; Haack et al., 2019; Storbacka et al., 2016), which helps us to explain how meso-level outcomes (i.e., the smart service system and related uncertainty) are linked to the activities of actors (i.e., organizations) at the micro-level. Accordingly, we pose the following research question: What are the microfoundations of uncertainty reduction in multi-actor smart service innovation? 
To answer this research question, we conducted an interview study with 25 interviews. Through a grounded-theory-based interpretive data analysis (Gioia et al., 2013), we derived a multi-level theoretical model of multi-actor smart service innovation that identifies smart service innovation uncertainty as a property of actor-to-actor relationships on the meso-level, and observable activities of actors on the micro-level. We conceptualize these micro-level activities into the four aggregate dimensions of (1) managing multiactor complexity, (2) crafting a smart service offering, (3) developing a technical solution, and (4) ensuring economic viability. We found that these activities are carried out by the involved actors under conditions of uncertainty resulting in iterative uncertainty reduction, affecting the smart service system as the innovation outcome.

Our study yields the following contributions: First, we answer recent calls for research by investigating smart service innovation from a perspective that goes beyond a single organization or the provider-customer dyad and instead considers systems of actors (Ostrom et al., 2015; Sjödin et al., 2020b). Second, we add another level of detail to our understanding of smart service innovation by adopting the framework of Storbacka et al. (2016) to investigate actor engagement at the micro-level of smart service innovation. That is, we go beyond existing studies that remain on macroand meso-level perspectives when they empirically analyze generic roles (Ekman et al., 2016) and actor-role constellations in smart service innovation (Anke et al., 2020c). Third, by empirically investigating smart service innovation processes on a micro-level, we contribute to providing evidence-based design knowledge that can help advance SSE and digital transformation methodologies (Alt, 2019; Böhmann et al., 2014; Höckmayr \& Roth, 2017). Finally, we identify smart service innovation uncertainty as a mesolevel property and iterative uncertainty reduction as a core category from our interview data. Thereby, our findings link the previously separate research streams of innovation uncertainty (Jalonen, 2012; O'Connor \& Rice, 2013) and smart service innovation (Anke et al., 2020c; Beverungen et al., 2018). The practical implications of our study consider the staffing and collaboration management of innovation projects in multi-actor settings, the use of agile methods, as well as ensuring customer-centricity and economic viability as central objectives of managing smart service innovation uncertainty.

The remainder of this article is organized as follows. In the "Research background" section, we introduce key concepts related to multi-actor smart service innovation, innovation uncertainty, and the multi-level perspective inherent to microfoundations. Then, we explain our "Research approach". The "Findings" section presents our insights from the interviews along the four aggregate dimensions and the core category that leads to an integrated theoretical model in the end. Next, we provide a discussion of our theoretical contributions, study limitations, and practical implications (Discussion section). The article closes with conclusions and an outlook towards promising avenues for future research (Conclusions and outlook section).

\section{Research background}

\section{Multi-actor smart service innovation}

Smart service innovation is a particular kind of service innovation with smart service systems as its context. Service innovation, in general, is the process of changing the resource integration patterns of a service system in a way that is valuable to the actors involved (Edvardsson \& Tronvoll, 2013; Storbacka et al., 2016; Vargo et al., 2010) and perceived as new and as an improvement considering the actors' context (Jalonen, 2012). The outcome of service innovation processes can touch upon multiple dimensions (Plattfaut et al., 2015), including the general service concept or value proposition, client interfaces or touchpoints, delivery system and use of technology (de Jong \& Vermeulen, 2003), business partners and revenue models (den Hertog et al., 2010), as well as institutions and institutional arrangements (Edvardsson et al., 2018; Koskela-Huotari et al., 2016; Vargo \& Lusch, 2016). Smart service innovation processes put a natural focus on the use of digital technology in service systems, but they usually also affect multiple of the other dimensions when they aim to establish new and better ways of co-creating data-driven value (Beverungen et al., 2019b; Djellal \& Gallouj, 2018; Edvardsson et al., 2018; Maglio \& Lim, 2018). Hence, the outcome of smart service innovation can manifest in a substantial change of an actor's business model (Barrett et al., 2015; Paschou et al., 2020; Wünderlich et al., 2015) as well as in the collective shaping of service ecosystems by multiple actors (Vink et al., 2021).

Especially in the context of digital transformation, it is argued that innovation outcomes rather evolve from a network of actors (including the customer but also other actors) than from a single organization alone (Lusch \& Nambisan, 2015). Thus, service innovation often involves the cooperation of multiple actors who contribute diverse resources to the service system (Edvardsson et al., 2018; Schymanietz \& Jonas, 2020) and whose interplay during the innovation process influences subsequent events (Jalonen, 2012). This complex, dynamic and multi-actor nature of value co-creation and service innovation is central to S-D logic's service ecosystems perspective (Vink et al., 2021). Following S-D logic, "innovation is not about inventing things but about developing systems for value cocreation" (Vargo \& Lusch, 2017 , p. 54). Taking up these lines of thought, Edvardsson et al. (2018) emphasize that service innovation has to 
be viewed from the perspective of multiple actors and the institutional arrangements they are embedded in.

The term actor refers to any market participant that is involved in actor-to-actor exchanges that create mutual value (Vargo \& Lusch, 2016). Hence, it can refer to human individuals or collections of humans, such as firms or organizations (Storbacka et al., 2016; Story et al., 2011), all of which can be understood as service systems themselves (Maglio et al., 2009). Actors can be internal or external to a focal organization (Schymanietz \& Jonas, 2020), with internal actors usually referring to different entities, roles, and functions within an organization, e.g., sales and service personnel, top management, or local branches (Schymanietz \& Jonas, 2020). Storbacka et al. (2016) further argue that machines and technologies should also be considered as actors due to current advances in autonomous technologies that reshape actor-to-actor interactions. Roles can be defined as "distinct technologically separable, value-added activities undertaken by firms or individuals" (Kambil \& Short, 1994, p. 10) that reflect "clusters of behaviors expected of parties in particular statuses or positions" (Knight \& Harland, 2005, p. 282). Actors can have multiple different roles simultaneously and the assignment of roles to actors can change dynamically over time (Ekman et al., 2016; Storbacka, 2019). Storbacka (2019) further argues that digitalization increasingly blurs previously strict actor roles (e.g., customer vs. non-customer, producer vs. consumer, or seller vs. buyer) and that all actors, viewed from an abstract viewpoint, have comparable processes of engagement in actorto-actor relationships, reflecting the idea of generic actors in S-D logic (Vargo \& Lusch, 2011). This idea, however, does not imply that all actors are identical. Rather, S-D logic refrains from assigning predefined or static roles to actors (Vargo \& Lusch, 2016).

Recent research has already shed some light on the roles of actors in smart service innovation and related fields and how they can change dynamically (Anke et al., 2020c; Ekman et al., 2016; Floerecke et al., 2020; Papert \& Pflaum, 2017; Riasanow et al., 2021; Schymanietz \& Jonas, 2020). Anke et al. (2020c) specifically look at the roles that different organizations can hold in a service ecosystem for smart service innovation. They distinguish between three types of actors: customers (both individuals and organizations), provider organizations (those organizations that intend to provide a novel smart service offering to customers), and external organizations (which mainly refer to IT service providers and IT consultants in their study). They identify 17 roles in total that these actors can assume. These are grouped into primary (e.g., Project Sponsor, Digital Innovator) and secondary roles (e.g., Customer Representative, Data Analytics Specialist, Cloud Platform Provider). Other studies identify roles with a stronger focus on digital technologies, including Internet of Things (IoT) services in supply chain management (Papert \& Pflaum, 2017), cloud computing ecosystems (Floerecke et al., 2020), and platform ecosystems (Riasanow et al., 2020).

\section{Innovation uncertainty}

The evolution of service ecosystems is considered to be nonlinear and dynamic, and "filled with risk and uncertainty" (Vargo \& Lusch, 2017, p. 61) Uncertainty is inherent to any innovation process (Jalonen, 2012) and, hence, also to smart service innovation. Despite the positive connotations associated with the concept of innovation, it has been described as a process of muddling through where the involved actors step into the unknown (Hurst, 1982; Jalonen, 2012; Rehn \& Lindahl, 2012). Uncertainty, in general, can be considered as a potential deficiency in any phase or activity of a process that is not definite, not known, or not reliable (Kreye et al., 2012). It is usually distinguished from the notion of risk in that no probability can be assigned to uncertainty, while risk is defined as a measurable unknown (Jalonen, 2012).

For the smart service innovation process uncertainty means that the multiple actors, who engage with each other, may lack the necessary understanding to make decisions because future states of the smart service system may be highly variable and unpredictable (Kreye et al., 2012; Ramirez Hernandez \& Kreye, 2021). The speed of technological developments, rapid changes in customer requirements, and competitive developments in the market have been identified as potential sources of uncertainty in service innovation (van Riel et al., 2004). In a smart service system, uncertainty can also arise because actors are required to manage interdependencies of product logic and service business logic in parallel ( $\mathrm{Ng}$ et al., 2012; Ramirez Hernandez \& Kreye, 2021). The involvement of multiple actors further increases complexity in the supplier network as well as uncertainty regarding the appropriate strategic level of supplier collaboration (Ramirez Hernandez \& Kreye, 2021). In the end, all of this renders the future realization of potential value to the various beneficiaries of a smart service system uncertain. In fact, substantial investments in extending the digital service business may not yield the required profits to be economically sustainable (Gebauer et al., 2005; Sjödin et al., 2020b).

Uncertainty is commonly understood as a multidimensional concept. Existing literature describes different factors, types, or categories of uncertainty in innovation processes (Jalonen, 2012; O'Connor \& Rice, 2013; Ramirez Hernandez \& Kreye, 2021). In the context of multiactor service systems, Ramirez Hernandez and Kreye (2021) develop a conceptual framework of five uncertainty types, which are environmental, technical, organizational, resource, and relational uncertainty (Table 1). Generally, 
a categorization of sources and types of uncertainty is difficult because they are interdependent (Jalonen, 2012; O'Connor \& Rice, 2013). This becomes evident from innovation processes where technological developments (e.g., in terms of a smart product) are combined with the market introduction, adoption, and dissemination of digital service offerings (Jalonen, 2012), which is common for smart service systems.

Ramirez Hernandez \& Kreye (2021) investigate case studies of inter-organizational multi-actor settings and analyze the influence of two different supplier co-creation modes on the criticality of the various uncertainty types (Table 1). The main difference between these two modes is whether the majority of the service innovation process is mainly done in-house of the focal organization with some non-critical input from other actors only, or if multiple actors share responsibility and exhibit close cooperation during the innovation process (Ramirez Hernandez \& Kreye, 2021). In the latter case, actors take the responsibility for subsystems (e.g., a product or service component, or software), with a need for subsequent integration into the overall service system. According to their case study findings, the mode with close involvement and shared responsibility shows higher levels of criticality for technical and relational uncertainty. However, this mode enables the focal organization to reduce resource uncertainty through a deeper engagement with other actors (Ramirez Hernandez \& Kreye, 2021). Environmental and organizational uncertainty appear to be always of high criticality independent of the co-creation mode. The two modes show similarities to the distinction of Anke et al. (2020c) regarding the involvement of actors with primary and secondary roles in smart service innovation. These modes indicate that actor engagement in a service ecosystem can differ according to different forms of resource contributions and that the management of actor engagement is a strategic priority (Storbacka, 2019).

Literature from different academic fields has discussed strategies to manage uncertainty (Miller, 1992; Simangunsong et al., 2012; Sniazhko, 2019). Simangunsong et al. (2012) distinguish between the two broad categories of reducing uncertainty and coping with uncertainty. While the former strategies intend to reduce uncertainty at its source (e.g., by applying pricing mechanisms to reduce customer demand fluctuation), the latter tries to find ways to adapt and minimize the impact of uncertainty (e.g., through advanced forecasting techniques to predict customer demand; Simangunsong et al., 2012). Existing studies show that information gathering is a key strategy that supports the reduction of decision-making uncertainty in service innovation processes, which, in turn, is associated with the likelihood of innovation success (van Riel et al., 2004). In the context of digital servitization, Sjödin et al. (2020b) suggest incremental investments, sprint-based developments, and 'learning by doing' to manage uncertainty when developing customized and scalable digital service offerings. Apart from uncertainty management strategies, Ramirez Hernandez and Kreye (2021) introduce the concept of uncertainty reallocation, which reflects that the variation of supplier co-creation modes as described above can shift the criticality between specific uncertainty types. For instance, actors might engage in relationships with others in seeking to reduce uncertainty but might fuel relational uncertainty at the same time (Jalonen, 2012).

Table 1 Uncertainty types (Ramirez Hernandez \& Kreye, 2021)

\begin{tabular}{ll}
\hline Uncertainty type & Description \\
\hline Environmental & - Unpredictability and variability of the external environment including customers, competitors, suppliers, and larger \\
& macro-developments in the industry \\
& - Supply and demand uncertainty \\
- Changes and disruptive effects on markets and the competitive landscape & - Degree of understanding required knowledge \\
Technical & - Design of a cost-efficient, reliable, and manufacturable technology platform (e.g., the smart product) \\
& - Complexity due to customization of the service part \\
& - Variability of the internal organization including the development team and the wider organization \\
& - Unpredictability of the strategic and operational flexibility of an organization \\
& - Changes in the strategic importance of a service offering concerning the organization's goals \\
& - Increased complexity in navigating the difference in the business logic between product and service-centered businesses \\
& - Understanding of novel roles, functions, and processes required for a new offering \\
- Unknown availability of appropriate financial, technical, and human resources used during development & - Variability in resource availability and unpredictability in resource attraction \\
Resource & - Ability to source capabilities and resources \\
& - Unpredictability of a collaborator's actions due to lack of understanding of the partner's attitudes, feelings, and behavior \\
Relational & Conflicts caused by ambiguity, opportunism, or conformity issues
\end{tabular}




\section{Multi-level perspective on managing uncertainty in smart service innovation}

The service ecosystems perspective of S-D logic implies that networks of actors can be seen at various levels of aggregation since service systems and ecosystems can be nested and overlapping (Vargo \& Lusch, 2017). Already when Spohrer et al. (2008) defined the service system as "a dynamic value co-creation configuration of resources, including people, organizations, shared information (language, laws, measures, methods), and technology, all connected internally and externally to other service systems by value propositions" (Spohrer et al., 2008, p. 318), they explained that their definition applies to entities at different levels of aggregation, ranging from the lowest level of individual humans as atomic service systems to the global economy. The service ecosystem concept further implies that more than two social actors interact with each other to co-create value (Vargo \& Akaka, 2012), which implies a departure from a dyadic view on value co-creation to more complex actor-to-actor networks as explained above. Following these thoughts, we view a service ecosystem as a service system at a higher level of aggregation that is a supra-system of other service systems (e.g., actors like individuals or organizations); or put differently as "systems of systems" (Storbacka et al., 2016, p. 3009). Disentangling the levels of aggregation, Vargo and Lusch (2017) suggest distinguishing between dyadic exchanges on a micro-level (e.g., transactions and sharing) and more complex constellations of direct and indirect exchanges on a meso- (e.g., triads, networks, industries, markets) and a macro-level (e.g., society) of aggregation. They also strictly separate between levels of aggregation and levels of abstraction. The latter refers to theoretical levels, where S-D logic resides on a meta-theoretical level with ambitions to serve as a general theory of the market and value co-creation (Vargo \& Lusch, 2017).

Taking a multi-level perspective on phenomena is at the heart of the microfoundations movement in strategic management and organization theory (Felin et al., 2015; Haack et al., 2019; Storbacka et al., 2016). Microfoundations locate "the proximate causes of a phenomenon (or explanations of an outcome) at a level of analysis lower than that of the phenomenon itself" (Felin et al., 2015, p. 587). That is, the actors, processes and/or structures at the micro-level may interact or operate alone to influence phenomena at the next upper (e.g., meso- or macro-) level (Felin et al., 2015). However, there are different understandings of the term microfoundations. Haack et al. (2019), for instance, identify three perspectives on (cognitive, communicative, and behavioral), and three conceptions of microfoundations (as agency, levels, or mechanisms) in the academic discussion. They argue that the least common denominator of a "microfoundational explanation comprises an analysis of multiple levels and the interaction across these levels." (Haack et al., 2019, p. 25) As micro and macro (as well as meso) are relative terms, any actor or entity can be micro in relation to something and macro in relation to something else (Haack et al., 2019). Therefore, it is important to explain one's understanding of micro- and macro-levels and why a given level is granted analytical primacy (Haack et al., 2019).

Storbacka et al. (2016) adopt the microfoundational view to conceptualize actor engagement as a microfoundation of value co-creation in service ecosystems. They define actor engagement as both an actor's exchange-based and nonexchange-based resource contributions in an interactive process of resource integration within a service ecosystem, which is facilitated by the actor's disposition to engage (Storbacka, 2019; Storbacka et al., 2016). The framework of Storbacka et al. (2016) consists of macro-, meso-, and micro-levels (Fig. 1), resembling the Coleman 'bathtub' (Felin et al., 2015). The macro-macro relationship of their framework defines value co-creation as an outcome of service exchange within the context provided by the institutional logic of a service ecosystem (Storbacka et al., 2016, p. 3009).

In their framework, Storbacka et al. (2016) understand microfoundations as mechanisms that provide explanations on why focal phenomena or effects occur on a superordinate level (Haack et al., 2019). Following the typology of social mechanisms by Hedström and Swedberg (1998), they distinguish between situational mechanisms (macro-mesomicro) that explain how higher-level conditions or contexts affect actors, action-formation mechanisms (micro-micro) that explain how an actor turns contextual conditions into
Fig. 1 Actor engagement as a microfoundation for value cocreation (Storbacka et al. 2016)

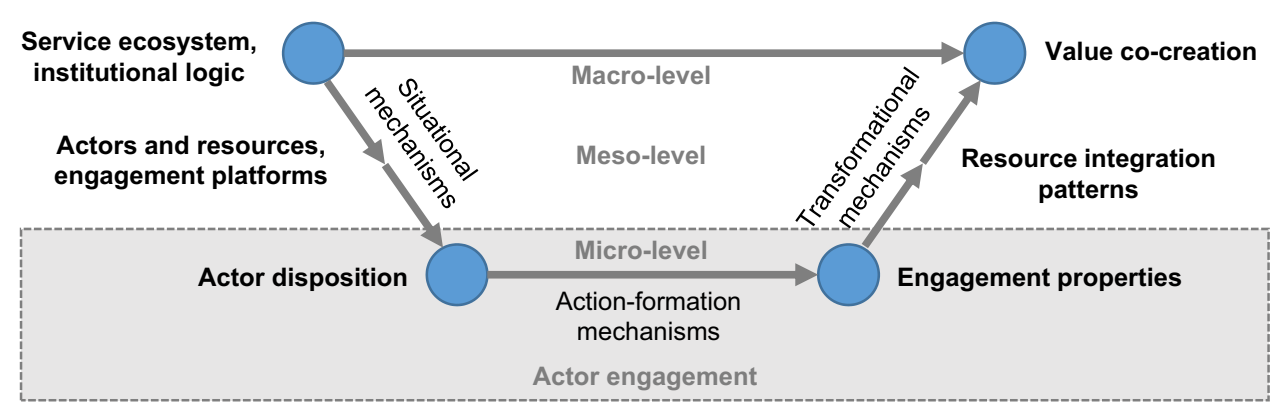


action, and transformational mechanisms (micro-mesomacro) that describe how multiple actors generate higherlevel outcomes through their actions and interactions (Storbacka et al., 2016). Looking at the relationship between the levels, the institutional logic of a service ecosystem provides the macro-level context for the interaction of actors with their resources on engagement platforms at the meso-level. Engagement platforms can be understood as virtual or physical "environments containing artifacts, interfaces, processes and people" (Storbacka et al., 2016, p. 3011), which serve as intermediaries of connections between actors and thereby facilitate, but do not participate in, actor engagement at the micro-level. Resource integration patterns emerge on the meso-level as a result of actor engagement on the microlevel. Finally, these lead to value co-creation by transforming the resource configurations of the actors in the service ecosystem (Storbacka et al., 2016). The framework by Storbacka et al. (2016) has already been found useful to guide service system design (Grotherr et al., 2018) and to inform future research on how service design can effectively enable stakeholder engagement in business-to-business innovation processes (Lievens \& Blažević, 2021).

For this study, we also decided to draw on the framework by Storbacka et al. (2016) as a theoretical lens to make sense of our qualitative-empirical data during data analysis. We specifically focus on the meso-and micro-level of smart service innovation. In line with our previous work, we understand actors as organizations (Anke et al. 2020c), where "a firm, using humans and technology, may engage with another firm's humans and technologies" (Storbacka et al., 2016, p. 3011). When multiple organizations engage in smart service innovation they form a smart service system and they usually set up a project (Anke et al., 2020c) that provides the engagement platform with engagement opportunities for the actors involved (Storbacka et al., 2016). Often, there is one focal actor with an Initiator (Ekman et al., 2016) or Project Sponsor role (Anke et al., 2020c) who initiates the project and invites further actors to create new value propositions as an outcome of the smart service innovation process (Ekman et al., 2016). Understood as the engagement platform, the project set-up provides artifacts, interfaces, and processes that facilitate resource integration and that the actors can use for their collaborative work (e.g., project management methodologies and tools) (Anke et al., 2020a). Actor engagement on the micro-level reflects the actual collaborative project work where the actors integrate their resources to change the resource integration patterns of the smart service system in a way that is valuable to them (Edvardsson \& Tronvoll, 2013; Storbacka et al., 2016; Vargo et al., 2010). Actor engagement on the micro-level is dependent on the actor's dispositions, that is, their intention and capacity to contribute resources in the specific project context (Storbacka et al., 2016). The joint project work results in changes in resource integration patterns on the meso-level. On the one hand, the actors generate smart service innovation outcomes in terms of resources like novel IT artifacts (e.g., a digital platform) and value propositions for targeted beneficiaries. On the other hand, they also shape future stages of their innovation activities by making decisions about what needs to be done in the smart service innovation project and who takes over responsibilities for work packages (e.g., by assigning tasks or subcontracting additional actors). Hence, the resource integration patterns of the project, understood as actor-generated institutions (Vargo \& Lusch, 2016), change through the joint project work, too. We argue that they are changed through actor engagement on the micro-level in a way that is supposed to iteratively reduce uncertainty on the meso-level.

\section{Research approach}

\section{Data collection}

We conducted an interview study to investigate actor engagement at the micro-level and its effects on multiactor smart service innovation at the meso-level. With this research objective, we focus on a subject matter for which empirical research is still very limited (Anke et al., 2020c; Ekman et al., 2016; Schymanietz \& Jonas, 2020; Sklyar et al., 2019). In the context of microfoundational research, our approach of a small-sample, qualitative and exploratory study is considered as particularly promising as it can lead to new theoretical developments (Felin et al., 2015), including more midrange theory in particular, which is still needed for further advancing research on S-D logic (Vargo \& Lusch, 2017). Hence, we contend that we follow a meaningful research approach that can yield novel insights and contribute to inductively building theory (Gehman et al., 2018).

Our data collection consisted of two rounds of interviews with experts as "knowledgeable agents" (Gioia et al., 2013, p. 17) who were involved in multi-actor smart service innovation. During the first round in 2018, we were interested in the roles that the different actors enacted in smart service innovation projects, reflecting the intersection of the macro- and meso-level of the framework by Storbacka et al. (2016). In the second round in 2020, we intended to capture the experts' activities and experiences in smart service innovation processes, that is, the actor engagement at the micro-level. We also took the chance to gather their reflections on further happenings concerning the projects they had reported about in 2018. Altogether, our goal was to gather information-rich data and to capture the breadth of activities of actors that can be observed in smart service innovation.

We identified appropriate experts for our interview study through a purposive approach (Eisenhardt, 1989; Yin, 2016). For the first round in 2018, we contacted those people in 
our personal network from whom we knew that they were involved in smart service innovation projects. We deliberately focused on practitioners and did not include fellow researchers in our study as we were interested in experiences from real-world smart service innovation processes. We deliberately approached potential experts from various industries and with different positions. This allowed us to cover the perspectives of various actors and roles. For the second round in 2020, we reached out to the same experts again and we were able to agree on a second interview with most of them. Some were not available for an interview this time or had moved to another employer and, therefore, were not part of the second round. At some other organizations, we were able to interview alternative or additional persons who could also report on the smart service innovation processes of their organizations.

In both rounds, we used semi-structured interview guidelines (Table 2) to stimulate the experts to report on their smart service innovation activities and experiences. As said, the first round of interviews focused on specific projects to be selected by the experts. The second round of interviews focused on the activities and interactions of multiple actors when collaborating in smart service innovation processes; we asked questions independently from specific projects to capture the experts' experiences across multiple projects in which they were involved.

In total, we conducted 25 interviews (Interview IDs in brackets in Table 3) with experts from 13 organizations. The first round comprises 14 interviews via phone from October 2018 to January 2019. The second round comprises eleven interviews that took place in July and August 2020 using phone and video meetings. We usually interviewed one expert per interview; except for interview 23, in which we talked to INTERNALIT's Project Manager and Data Scientist at the same time. The duration ranges from 40 to 103 minutes per interview, with a total of 29 hours of audio recordings. All interviews were transcribed for our detailed analysis. Throughout this paper, we only provide organization pseudonyms and the expert's position as we guaranteed anonymity to them (Table 3 ). As an indication of the company size, we provide their number of employees in the following five categories: A: <50; B: 51-250; C: 251 to 1000; D: 1001 to $10000 ; \mathrm{E}:>10000$.

\section{Data analysis}

We conducted a first thorough analysis after the first round of data collection, which resulted in the identification of 17 roles that actors can assume in smart service innovation. These results have already been published (Anke et al., 2020 b, c). For this follow-up study, we applied the Gioia methodology as a widely accepted approach to groundedtheory-based interpretive research (Gehman et al., 2018; Gioia, 2021; Gioia et al., 2013). We extended our data sample with eleven additional interviews from the second round. We employed MaxQDA as software support for coding the transcripts.

During our 1st-order analysis (Gioia et al., 2013), all three researchers went through the transcripts individually. We inductively assigned descriptive open and in-vivo codes to passages that provide information about the activities and collaboration of multiple actors in smart service innovation. When coding, we tried to closely adhere to the terms of our informants (Gioia et al., 2013), e.g., using code labels like "proxy product owner", "silo thinking" or "It is exciting to see how little the different departments actually talk to each other." We also revisited the interviews from the first round and assigned codes to those transcripts in the same way. In the second step of our 1st-order analysis, we jointly tried to make sense of the large number of codes, seeking similarities and differences, and aimed at a consensual understanding. Thereby, we reduced our vast amount of codes into a manageable number of 54 1st-order concepts (Gioia et al., 2013), which reflect the observable activities of actors that

Table 2 Interview guidelines

Interview guideline in 2018

1. Introduction of interviewer and expert, description of the expert's organization, expert's background, and his/her role in the organization.

2. Identification of smart service innovation projects, in which the expert was involved and selection of one project for closer analysis in the following sections of the interview.

3. Project initiation, including a general description of the project and the trigger for starting the project.

4. Project organization, including internal and external actors involved, the project management approach, employed methods, and specifications made.

5. Project outcome, including the value proposition, operational process design, and resource configuration of the smart service system.
Interview guideline in 2020

1. Follow-up on the previous interview including a brief retrospective on the specific project from the initial interview.

2. Actors and roles that can be present in smart service innovation projects.

3. Multi-actor project management including methodologies, collaborative tools, and distribution/coordination of work across actors/roles.

4. Methods, techniques, and practices that are commonly used in smart service innovation projects. 
Table 3 Overview of expert interviews

\begin{tabular}{|c|c|c|c|c|}
\hline $\begin{array}{l}\text { Organization } \\
\text { pseudonym }\end{array}$ & $\begin{array}{l}\text { Organization description } \\
\text { (size category) }\end{array}$ & $\begin{array}{l}\text { Expert position in } \\
\text { organization }\end{array}$ & $\begin{array}{l}\text { Interview duration in } \\
2018 \text { (interview ID) }\end{array}$ & $\begin{array}{l}\text { Interview duration in } \\
2020 \text { (interview ID) }\end{array}$ \\
\hline ENERGYPLAT & $\begin{array}{l}\text { Digital platform provider for energy } \\
\text { management }(\mathrm{B})\end{array}$ & Head of Product Management & $1: 30 \mathrm{~h}(01)$ & 1:05 (15) \\
\hline INSURANCE & Insurance company $(\mathrm{E})$ & Project Manager & 1:04 h (02) & $1: 35 \mathrm{~h}(16)$ \\
\hline CITYMOBIL & Utilities and public transport (C) & Project Manager & $1: 29 \mathrm{~h}(03)$ & $-/-$ \\
\hline GLOBALSYS & Global IT solution provider (E) & $\begin{array}{l}\text { IT Architect and Consultant } \\
\text { Program Manager }\end{array}$ & $\begin{array}{l}1: 17 \mathrm{~h}(04) \\
1: 27 \mathrm{~h}(05)\end{array}$ & $\begin{array}{l}1: 43 \mathrm{~h}(17) \\
-/-\end{array}$ \\
\hline ENERGYTRADE & $\begin{array}{l}\text { Digital platform provider for energy } \\
\text { trading }(C)\end{array}$ & Project Manager & $1: 11 \mathrm{~h}(06)$ & $1: 41 \mathrm{~h}(18)$ \\
\hline ITSOLUTION & $\begin{array}{l}\text { IT solution provider, consulting, soft- } \\
\text { ware development (B) }\end{array}$ & Lead Architect & $1: 13 \mathrm{~h}(07)$ & $-/-$ \\
\hline ITCONSULT & IT consulting (D) & Program Manager & $0: 41 \mathrm{~h}(08)$ & $1: 24 \mathrm{~h}(19)$ \\
\hline DIGIBUSINESS & $\begin{array}{l}\text { IT and digital business solution pro- } \\
\text { vider (D) }\end{array}$ & $\begin{array}{l}\text { Member of the Project } \\
\text { Steering Board }\end{array}$ & $1: 06$ h $(09)$ & $-/-$ \\
\hline UTILCONSULT & Management consulting for utilities (B) & Team Lead for Digitalization and IT & $1: 14 \mathrm{~h}(10)$ & $-/-$ \\
\hline \multirow[t]{3}{*}{ PHARMACHINES } & \multirow[t]{3}{*}{$\begin{array}{l}\text { Machinery construction for the phar- } \\
\text { maceutical industry }(\mathrm{C})\end{array}$} & $\begin{array}{l}\text { Product Manager for } \\
\text { Service/Support }\end{array}$ & $0: 48 \mathrm{~h}(11)$ & $-/-$ \\
\hline & & Chief Innovation Architect & $-/-$ & $1: 03 \mathrm{~h}(20)$ \\
\hline & & Head of Digital Solutions & $-/-$ & $0: 40 \mathrm{~h}(21)$ \\
\hline PACKMACHINES & $\begin{array}{l}\text { Plant construction for packing food/ } \\
\text { non-food items (B) }\end{array}$ & Head of After Sales Service & $0: 41 \mathrm{~h}(12)$ & $1: 03 \mathrm{~h}(22)$ \\
\hline \multirow[t]{2}{*}{ INTERNALIT } & \multirow[t]{2}{*}{$\begin{array}{l}\text { Internal IT providers (two different } \\
\text { entities) of a large machinery manu- } \\
\text { facturer (D) }\end{array}$} & $\begin{array}{l}\text { IT Solution Consultant } \\
\text { Project Manager } \\
\text { Data Scientist }\end{array}$ & $\begin{array}{l}1: 00 \mathrm{~h}(13) \\
-/-\end{array}$ & $\begin{array}{l}-/- \\
1: 13 \text { h }(23)\end{array}$ \\
\hline & & UX Designer & $-/-$ & $0: 49$ h $(24)$ \\
\hline FIELDSERVICE & $\begin{array}{l}\text { Provider of field service management } \\
\text { software (A) }\end{array}$ & CEO & 1:04 h (14) & $1: 00 \mathrm{~h}(25)$ \\
\hline
\end{tabular}

our experts reported on, e.g., "identifying key stakeholders" and "taking a mediating role and solving conflicts", and, hence the actor engagement on a micro-level (Storbacka et al., 2016).

In our 2nd-order analysis, we further condensed the 1st-order concepts into 212 nd-order themes by constantly comparing the 1 st-order concepts and their underlying codes across the different interviews (Gioia et al., 2013; Hallberg, 2006). In this phase, we inductively searched for categories that help us describe the activities of actors. In addition, we also tried to identify to which roles these activities can be assigned to link the micro-level perspective of this study with the meso-level perspective reflected by the roles that Anke et al. (2020c) identified. Here, we deductively assigned the roles to our set of activities based on the descriptions as provided by our informants. We mainly identified the primary roles of the Project Sponsor (PS), the Digital Innovator (DI), and the System Integrator (SI). Furthermore, the Customer Representative (CR) also appeared to engage in smart service innovation, which reflects customer involvement as a key characteristic of agile project management approaches applied by some of our experts. Table 4 presents the definitions of the four roles (Anke et al. 2020c) that were particularly relevant during our data analysis.

In the further course of our 2 nd-order analysis, we distilled the 2nd-order themes into four aggregate dimensions (Gioia et al., 2013) that group the micro-level activities of actors into categories on a higher level of abstraction (e.g., "managing multi-actor complexity"; see Fig. 2). Finally, we decided on selecting "iterative uncertainty reduction" as our overarching core category because the 2nd-order themes resembled some associations with the types of innovation uncertainty that have been put forward in existing literature (O’Connor \& Rice, 2013; Ramirez Hernandez \& Kreye, 2021). When making sense of this core category we also found that it was mainly a property that refers to the actorto-actor network with its resources and resource integration patterns, reflecting the meso-level of the framework by Storbacka et al. (2016), while the activities that we coded referred to the actor engagement on the micro-level. Hence, 
Table 4 Roles relevant to our study (Anke et al., 2020a)

\begin{tabular}{|c|c|c|}
\hline Role & Key & Activities in the service ecosystem \\
\hline $\begin{array}{l}\text { Project } \\
\text { Sponsor }\end{array}$ & PS & $\begin{array}{l}\text { - Initiates, sponsors, and often manages the overall project } \\
\text { - Operates and offers the service towards the service beneficiary after completion of the smart service } \\
\text { innovation project }\end{array}$ \\
\hline $\begin{array}{l}\text { Digital } \\
\text { Innovator }\end{array}$ & DI & $\begin{array}{l}\text { - Provides methodological support for the innovation process } \\
\text { - Facilitates the creation of service ideas } \\
\text { - Designs business model }\end{array}$ \\
\hline $\begin{array}{l}\text { System } \\
\text { Integrator }\end{array}$ & SI & $\begin{array}{l}\text { - Develops technical concept, e.g., system architecture } \\
\text { - Develops front-end, e.g., apps, and backend services, e.g., cloud analytics and other software components } \\
\text { - Integrates existing systems, services, and devices }\end{array}$ \\
\hline $\begin{array}{l}\text { Customer } \\
\text { Representative }\end{array}$ & $\mathrm{CR}$ & $\begin{array}{l}\text { - Informs the project as a target customer of the value proposition } \\
\text { - May be involved at various stages of the project, e.g., to provide feedback during development }\end{array}$ \\
\hline
\end{tabular}

we decided to adopt their multi-level view to explain how activities of actors and uncertainty reduction relate to each other in smart service innovation. That is, the core category explains the underlying rationale of actors why and how they engage with other actors (reflecting the actors' dispositions and their engagement). At the same time, the core category is the intended outcome of actor engagement, leading to changes in the actor-to-actor network and resource integration patterns on the meso-level. Hence, the core category "determines and delimits the theoretical framework" (Hallberg, 2006, p. 144) of smart service innovation that we suggest.

\section{Findings}

\section{Overview}

The interviewees shared their experiences from a wide range of smart service innovation processes. The smart service offerings that they implemented include mobility and vehicle charging services for citizens, remote support services for industrial equipment, as well as digital platforms for vehicle delivery tracking or energy trading, to mention just a few. The starting points and target states of the smart service innovation processes varied. Some were able to build on an already existing advanced digital infrastructure, making it comparatively easy to exploit technological options for adding further digital service offerings. Others rather followed an explorative approach, which also involved getting an understanding of technological options and meaningful customer problems in the first place.

Independent of such differences, our interviewees consistently reported on the involvement of multiple actors in their smart service innovation projects. As also reflected by our sample of interviewees, the key actors comprise provider organizations that intend to create new value propositions for their customers as well as IT service providers and IT consultancies (simply called IT firms in the following) that support them in realizing digitally-enabled service offerings. Further relevant actors are customers that represent the target market as well as other firms and freelancers, whose expertise and capacities are required to successfully implement the smart service system. The different actors take on different roles in smart service innovation processes. For instance, it is common that the provider organization assumes the roles of the Project Sponsor and contracts an IT firm to take on the roles of Digital Innovator and System Integrator. Some other provider organizations keep more of these roles in-house. Similarly, IT firms may source expert knowledge and further resources from third parties that thereby also take over specific roles and engage in smart service innovation, too.

In the following, we report on the activities that multiple actors with different roles enact to engage with each other in smart service innovation. We structure the overall set of concepts and themes along the four aggregate dimensions of (1) managing multi-actor complexity, (2) crafting a smart service offering, (3) developing a technical solution, and (4) ensuring economic viability (Fig. 2). Finally, we illustrate how this actor engagement on a micro-level supports iterative uncertainty reduction in the actor-to-actor network of smart service innovation projects on the meso-level by presenting an integrated theoretical model.

\section{Managing multi-actor complexity}

The multi-actor setting in smart service innovation can be considered complex because a diverse set of actors (e.g., as regards expertise, resources, and organizational culture) works together to put the smart service system in place. Their different activities have to integrate smoothly to meet 


\section{1st-order concepts}

2nd-order themes

Aggregate dimensions

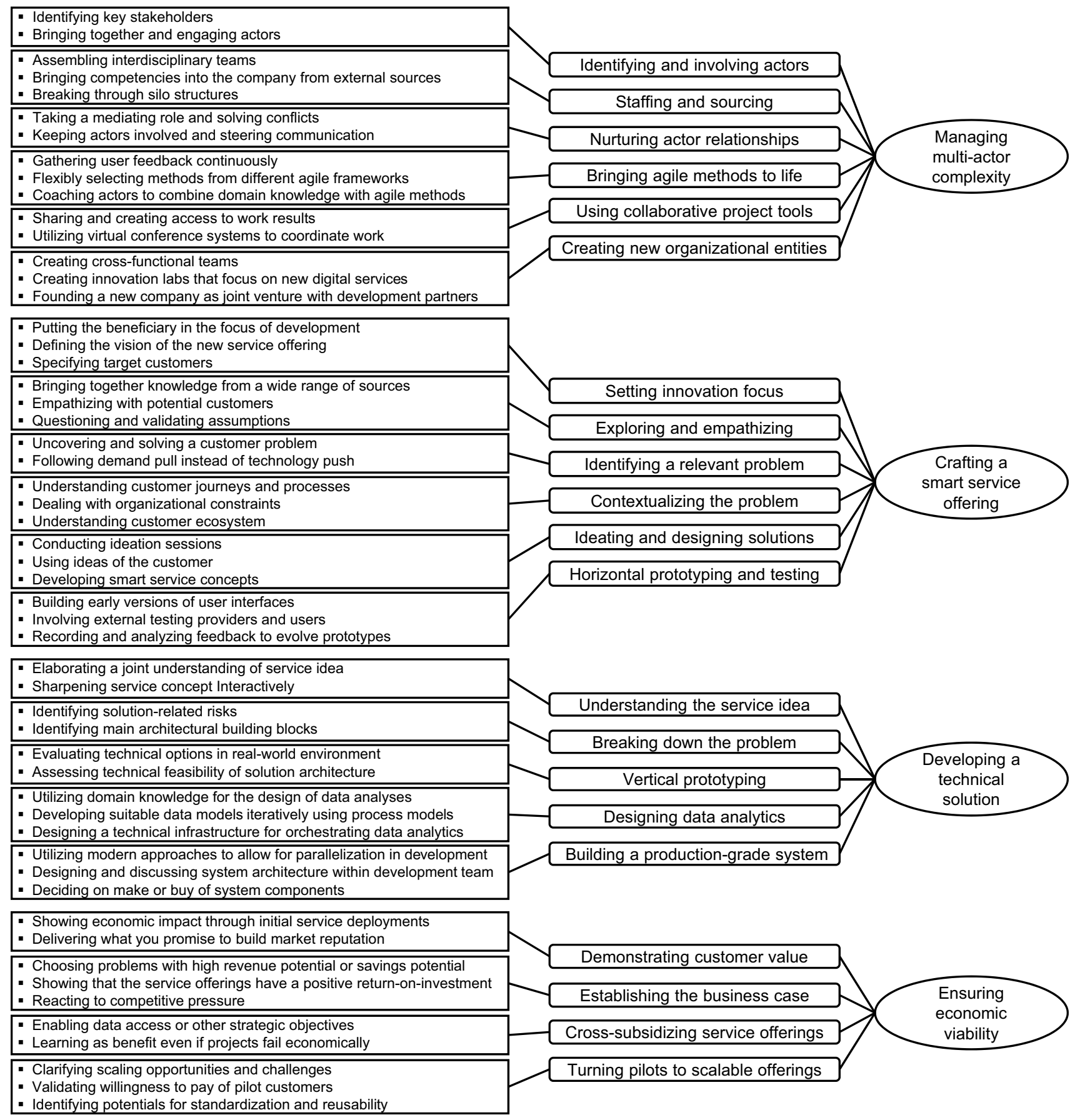

Fig. 2 Data structure

the time and budget constraints that are usually defined for smart service innovation projects.

First of all, our interviewees emphasize that it is important to identify and involve actors. Key stakeholders need to be identified and actors are invited to engage. A meaningful approach is to bring everyone to one table in a kick-off workshop.
"You really take a day and get all the actors who could foreseeably be involved in the project together at one table.” (ENERGYTRADE, Project Manager, 2020)

Particular dedication is put on the different departments that are usually involved at the provider organization that holds the Project Sponsor role, which can be numerous. 
"Yes, as I said, there are several departments from the customer involved, all of which have different requirements.” (ITCONSULT, Program Manager, 2018) “

Project Sponsors themselves even admit that communication across departments is an issue in smart service innovation projects. IT firms with the System Integrator role further emphasize that they have to involve the Project Sponsor's IT department early on to get consent for the planned technical implementations. Gaining their consent, however, can be a challenge.

\section{"Their own IT department. This is the big brakeman in the whole game because they are drowning in work, have security concerns, and do not have resources." (FIELDSERVICE, CEO, 2020)}

Although our interviews showed that it is not uncommon that smart service innovation projects are carried out without involving actors with the Customer Representative role, enduser involvement is generally perceived as a plus. Again, this does not always come for granted:

"Ideally, you will also have pilot customers who will join the project. But of course it's not quite that simple. Because they have to find some time." (FIELDSERVICE, CEO, 2020)

Staffing and sourcing is another theme that is required to manage the collaboration with multiple actors. On the one hand, decisions have to be made at each actor about the internal staffing for the project. Here, the interviewees mostly rely on interdisciplinary teams and try to dissolve existing silo structures. Additionally, external sourcing is needed in many cases because of limited internal competencies or capacities. We already find such a sourcing decision in the case where an actor with the Project Sponsor role contracts an external IT firm to take over the System Integrator role. In some cases, external specialists are needed that can cope with certain implementation challenges. But also the IT firm's available resources can be limited, leading to the assignment of freelancers and other firms to help out.

"When it comes to cloud connectivity now, implementing China is a complicated story. And this is usually only possible in cooperation with the relevant experts from the cloud platform providers. [..] Other constellations are simply a scaling, that one says, one strengthens oneself with personnel, if one is short in the area." (ITCONSULT, Program Manager, 2020)

A further theme is to nurture actor relationships. A key person in this regard can be the project manager who tries to keep all strings together, although the traditional role of a project manager might not be present anymore in modern agile methodologies. The interviewees try to solve conflicts, motivate, and keep all actors involved in the project, e.g., by steering communication.

"In this context one thing is important. And that is bringing together external partners and internal employees and the customer. I have a central role, so to speak, and have to bring everything together to the right and left. And if everything works out smoothly, if no one is disappointed and we have found good compromises for everyone, if everyone is ultimately satisfied after a project like this, i.e., if not only the customer needs have been matched, but also the internal processes are in a way that the product also works very well for our internal employees and the partners were also on schedule, then I believe it is a good project in the end." (PHARMACHINES, Chief Innovation Architect, 2020)

The interviewees reported on different project management methodologies that they use in smart service innovation processes, basically including three variants: sequential (waterfall), agile and hybrid approaches, with the latter combining elements of the former two approaches. We observed that the interviewees reported on the growing popularity of agile approaches, especially when we compared the interviews from 2018 with those from 2020. At the IT firms, agile methods are nowadays perceived as the standard approach to developing solutions.

"It must be said that in projects that can be called successful projects, [..] a real agile model was driven quite strictly and successfully. And that has been one of the success factors." (ENERGYPLAT, Head of Product Management, 2020)

However, in the multi-actor settings as reported in our interviews, we saw that not all actors are equally knowledgeable about these methods, especially considering traditional manufacturing organizations that hold the Project Sponsor role. Consequently, we identified the theme of bringing agile methods to life. Many agile methods and frameworks including Design Thinking, Scrum, Lean Startup, or Design Sprints were mentioned. Often, just elements from the approaches were selected and integrated. One aim was to get continuous feedback to avoid developing in the wrong direction. The actors with the Digital Innovator and System Integrator roles also had to clarify the implications of agile methods for all other actors involved in the project. The interviewees mentioned, e.g., experienced domain experts who carry important knowledge for smart service innovation but often have to be introduced to agile methods and trained to use them. As there usually are different levels of experience and expertise with agile methods, the recommendation was to adjust methodologies flexibly to ensure that all actors still feel comfortable. 
"Our goal is to work agile. [..] And it is not set in stone how we work, but we look at how we use the tools, which agile methods, whether we work according to Scrum, whether we work according to Kanban or other. We look at that and then choose what makes the most sense for the team." (INSURANCE, Project Manager, 2020)

Sometimes, inter-organizational settings also require deviating from the role definitions that agile methods propose. The IT firms try to assign the product owner role to their customers as devised in Scrum, but sometimes have to establish a so-called "proxy product owner" (GLOBALSYS, IT Architect and Consultant, 2020) at their organization in cases where the customer (or the actor with the Project Sponsor role) is neither able nor willing to act as the product owner. Generally, the introduction of agile methods into a multi-actor setting was sometimes considered a particular challenge.

"And, of course, this also makes us a bit of a two-speed company. We have our classic rhythms of innovation in mechanical engineering, and my department is simply in much shorter loops, so we have basically found two points in the default process for us, where we can always incorporate this in an agile manner." (PHARMACHINES, Head of Digital Solutions, 2020)

The interviewees from IT service provider organizations consistently reported on the use of collaborative project tools, which serve as central platforms for all actors involved, including externally sourced freelancers and firms. This activity is based on the necessity to share work results with all actors involved and to communicate with multiple actors. Here, online conferencing and project management software tools are implemented.
"We try to include all service providers in Jira [..] And they can be from different organizations. [They] can also be freelancers and so on. But the goal is that we have a common view on the whole topic. And ideally, as in agile by the book, we also share this with the client." (GLOBALSYS, IT Architect and Consultant, 2020)

In addition to Jira, it is also Confluence which was commonly mentioned as one of the collaborative project tools. Confluence is perceived as a tool that is easy to use even for non-developers. Such tools can also be used by the Project Sponsor role to provide input (e.g., by filling the product backlog). Some other Project Sponsors even predefine the complete development environment and project tools that the System Integrators are obliged to use.

Finally, we also identified creating new organizational entities as a theme from our interview data. One approach was the establishment of an interdisciplinary team with about ten employees from different departments at PHARMACHINES that try to identify customer problems and then develop initial prototypes in design sprints. ENERGYTRA DE even founded a new company with partners to have an adequate organizational shell for their smart service offering. A third possibility was presented by INTERNALIT who built up a dedicated innovation lab that focuses on digital services. Table 5 summarizes the themes with the involved roles and related concepts.

\section{Crafting a smart service offering}

Smart service innovation involves crafting a smart service offering that attracts customers and has the potential to solve relevant customer problems. A key aspect of this area is customer involvement. Some experts emphasized that they

Table 5 Themes, roles, and concepts for "Managing multi-actor complexity"

\begin{tabular}{|c|c|c|}
\hline Themes & Roles & Concepts \\
\hline Identifying and involving actors & PS, SI & $\begin{array}{l}\text { - Identifying key stakeholders } \\
\text { - Bringing together and engaging actors }\end{array}$ \\
\hline Staffing and sourcing & PS, SI & $\begin{array}{l}\text { - Assembling interdisciplinary teams } \\
\text { - Bringing competencies into the company from external sources } \\
\text { - Breaking through silo structures }\end{array}$ \\
\hline Nurturing actor relationships & PS & $\begin{array}{l}\text { - Taking a mediating role and solving conflicts } \\
\text { - Keeping actors involved and steering communication }\end{array}$ \\
\hline Bringing agile methods to life & SI, PS, DI & $\begin{array}{l}\text { - Gathering user feedback continuously } \\
\text { - Flexibly selecting methods from different agile frameworks } \\
\text { - Coaching actors to combine domain knowledge with agile methods }\end{array}$ \\
\hline Using collaborative project tools & SI, PS & $\begin{array}{l}\text { - Sharing and creating access to work results } \\
\text { - Utilizing virtual conference systems to coordinate work }\end{array}$ \\
\hline Creating new organizational entities & PS & $\begin{array}{l}\text { - Creating cross-functional teams } \\
\text { - Creating innovation labs that focus on new digital services } \\
\text { - Founding a new company as a joint venture with development partner }\end{array}$ \\
\hline
\end{tabular}


try to follow a customer-centric approach whenever possible. Such a mindset turns out to be challenging to implement, as companies are used to existing industry logic and ways of working. However, the relevance was underpinned by the fact that projects can fail due to a lack of customer orientation.

"It is an unusual thought for a mechanical engineer not to think so much about what is technically possible and what would be fancy, but to think: 'What does the customer actually want?' [..] For [us], it is totally counter-intuitive, normally we hide in our chamber for six years, develop the greatest machine in the world and it has to work completely when we take it out to customers." (PHARMACHINES, Head of Digital Solutions, 2020)

"The biggest mistake [we] could have made. It was developed because we liked it and not because the customer needed it. The approach was wrong from the start." (PACKMACHINES, Head of After Sales, 2020)

In the following, we present the activities that we identified for crafting a smart service offering. In most cases, these were observable from actors with the Project Sponsor or Digital Innovator roles who also involved Customer Representatives. Especially in the early phase of innovation initiatives, defining a vision for the service offering is one key action the participants mentioned. Also, the selection of a target user group seems essential. We summarized such activities under setting innovation focus. User groups can be selected based on various criteria, e.g., financial or geographic aspects.

"And there was just a user group that we chose. Users who, if you look at it from a purely economic point of view, constantly generate costs. We also have the goal of reducing costs and one way of doing this is to take precautions to actively support the customer." (INSURANCE, Project Manager, 2020)

Exploring and empathizing covers activities that bring together a great variety of knowledge of different sources needed for innovation. A huge part is about understanding potential customers. Project Sponsors and Digital Innovators draw on the expertise of UX designers or have the required expertise themselves. The interviewees reported that they conduct exploratory interviews or do observations in the field for an unbiased analysis of the processes and pain points of the target customer. Problems and needs of the customers are identified through listening, observation, and targeted questioning. The aim is to avoid making decisions based on assumptions or to at least substantiate or prove assumptions by gathering as much information as possible.
Here, the interviewees pointed out that it is necessary to force oneself not to propose solutions or to have them in mind.

"A design thinking expert and one of our salespeople went there and asked a little bit of a prepared questionnaire, but a lot was about really understanding: Okay, why does this bother you? What do you do then? What is the situation exactly? Not only to take away what the customer wants but also to really say: I have understood what annoys him so that my ideas really hit the nerve afterward. " (PHARMACHINES, Head of Digital Solutions, 2020)

It is also interesting to note that these activities were considered particularly important, as they lay the foundations for further activities. Actors therefore also want to deploy more resources in these phases.

"In any case, I would first of all talk more intensively with the customer, potential users. I would do very extensive user experience research to understand the customer holistically. And only then would you be able to plan the project properly." (INTERNALIT, Project Manager, 2020)

Identifying a relevant problem describes the activity of uncovering and solving significant customer problems. While some build on a very detailed exploration as described above, others make assumptions and considerations about customer needs and constantly change between solution generation and problem assessment. However, it became clear that innovation should not follow a technology push but a demand pull. Especially after very extensive exploration, the data can be overwhelming, which is why organizations try to synthesize information into a problem to solve.

"What I like to do before that is an NABC. An NABC says okay, what is my target group? Then I think about the target group: What is the need of the target group? In other words, what is it that drives them around, what would they be willing to pay money for, or what offers them added value? Then I would have the approach, that is, how do I serve this added value? What is actually my solution? Then I consider: What is the benefit of my solution and what is the benefit for the target group? What do they get out of it?" (GLOBALSYS, IT Architect and Consultant, 2020)

"In the end, it is difficult to achieve a reasonable synthesis, because you always have this bias of two to three interviews, which stuck in your head. [..] We have a [method which] gives you a relatively quick overview of which customer said what. [..] We try to take all points of view and actually have a brainstorming session. We [..] make a problem statement. That 
means we frame the problem again in two sentences" (PHARMACHINES, Chief Innovation Architect, 2020)

Different contexts and restrictions hamper smart service innovation and therefore need to be considered and understood, which we label contextualizing the problem. Even though it seems that most problems apply across industries, the specifics of certain industries should not be underestimated. To tackle such challenges, it is necessary to analyze customer processes, whole ecosystems, and various contextual conditions. Organizational constraints can appear due to data security issues, regulations, or process certifications, e.g., in the pharmaceutical industry where PHARMACHINES operates. By contextualizing the problems, hurdles can be identified and addressed already at an early stage.

"That's why I like to do these interviews in context. So, I really run for a day, or a few hours, depending on how much time they can give me. They can work all the time. Sure, I ask things from time to time, but otherwise? I just observe a lot. I just observe the whole day." (INTERNALIT, UX Designer, 2020)

Ideating and designing solutions subsumes activities that refer to the use of creativity methods and brainstorming sessions but also includes activities to conceptualize offerings regarding its value proposition or business model. Although organizations try to focus on the desirability for the target customer, ideas have to be developed considering technological possibilities, because, in the end, it is also about being able to offer working solutions. Instead of developing new ideas internally, they can also be picked up from the customer. All in all, it is a matter of developing a suitable solution, which can also rely on third-party providers and existing solution elements.

\section{"We will build on the user experience research results and see which smart services we can help the customer with, but this still goes hand in hand with the techni- cal planning. In other words, this is what I want, this is what the customer wants. But how could we even map this with the database that is available to us?" (INTERNALIT, Project Manager, 2020) \\ "This does not necessarily have to be a new develop- ment, [..] you just have to provide it." (ENERGYPLAT, Head of Product Management, 2020)}

Finally, horizontal prototyping and testing is the building and testing of early versions of user interfaces. Prototyping techniques like wireframes or click dummies can help to implement ideas and solutions quickly. A lot of insight and feedback should be generated with as little effort as possible. Too detailed and fully developed prototypes are even described as an obstacle to feedback.

"I just do everything on paper first. Actually, because then I can throw it away the easiest and fastest way. "

(INTERNALIT, UX Designer, 2020)

Prototypes are handed over to the Customer Representative for testing and gathering feedback for improvement. Also, external testing providers and users can be involved to gain feedback.

"There are providers who enable test scenarios, that means you give them, for example, an app and the app is then released to numerous users and they can give feedback over a platform" (INSURANCE, Project Manager, 2018)

Such feedback is recorded and analyzed to further evolve prototypes. Such an iterative approach is considered important in order not to develop in the wrong direction or to be able to counteract.

"Feedback is then incorporated and the prototype is given another depth, another sharpness. This goes from low-fidelity to high-fidelity and then we test it again." (PHARMACHINES, Chief Innovation Architect, 2020)

Table 6 summarizes the activities with the involved roles and related concepts

\section{Developing a technical solution}

As smart service systems are socio-technical systems, the technical resources of such systems need to be designed and implemented, too. The activities to develop a suitable technical solution for the planned service includes, for example, the selection of technologies and frameworks, assessing the feasibility of a technical approach and the satisfiability of non-functional requirements, and managing the required efforts. From the analysis of our interviews, we identified the following themes, which usually refer to activities performed by the actor (typically an IT provider organization) with the System Integrator role. However, in some cases, the actor with the Project Sponsor role had the resources to also assume this role and perform these activities itself.

In case that an external IT provider organization assumes the System Integrator role, this actor is often confronted with existing service ideas that were developed by other actors with Project Sponsor or Digital Innovator roles. Therefore, one activity of Systems Integrators is understanding the service idea. To build a technical solution, a joint understanding between Project Sponsor and System Integrator has 
Table 6 Themes, roles, and concepts for "Crafting a smart service offering"

\begin{tabular}{|c|c|c|}
\hline Themes & Roles & Concepts \\
\hline Setting innovation focus & PS, DI & $\begin{array}{l}\text { - Putting the beneficiary in the focus of development } \\
\text { - Defining the vision of the new service offering } \\
\text { - Specifying target customers }\end{array}$ \\
\hline Exploring and empathizing & PS, DI, CR & $\begin{array}{l}\text { - Bringing together knowledge from a wide range of sources } \\
\text { - Empathizing with potential customers } \\
\text { - Questioning and validating assumptions }\end{array}$ \\
\hline Identifying a relevant problem & PS, DI, CR & $\begin{array}{l}\text { - Uncovering and solving a customer problem } \\
\text { - Following demand pull instead of technology push }\end{array}$ \\
\hline Contextualizing the problem & PS, DI, CR & $\begin{array}{l}\text { - Understanding customer journeys and processes } \\
\text { - Dealing with organizational constraints } \\
\text { - Understanding customer ecosystem }\end{array}$ \\
\hline Ideating and designing solutions & PS, DI, SI & $\begin{array}{l}\text { - Conducting ideation sessions } \\
\text { - Using ideas of the customer } \\
\text { - Developing smart service concepts }\end{array}$ \\
\hline Horizontal prototyping and testing & PS, DI, CR & $\begin{array}{l}\text { - Building early versions of user interfaces } \\
\text { - Involving external testing providers and users } \\
\text { - Recording and analyzing feedback to evolve prototypes }\end{array}$ \\
\hline
\end{tabular}

to be elaborated. Such understanding is to be sharpened by an iterative concept building. Typically, this takes place in an initial workshop.

"The customer usually has an idea, a rough direction where he wants to go. What we do there is, first of all, a workshop with the customer to better understand the idea, to sharpen it and ideally to split it up, in an agile sense into epics, to say okay, if that is your vision, into which basic components can you break it down?"

(GLOBALSYS, IT Architect and Consultant, 2020).

Once the basic idea and the scope of the task are understood, System Integrators try to break down the problem into smaller parts. This might involve the identification of major system components such as apps, backend, external systems, cloud services, and devices. Additionally, agile techniques such as epics and customer tasks are applied to describe the main building blocks of functionality. This helps to draft an initial project plan and identify both risks and required resources. Risks at this stage result from external dependencies, such as providers of external systems and hardware, which need to be integrated.

"When you integrate hardware and integrate other systems, it is important to start integrating these other systems or hardware at a very early stage, because that's where the risks lie, including certificate management and all the other issues: protection, security."

(GLOBALSYS, IT Architect and Consultant, 2020).

Another theme that we identified for the System Integrator role is vertical prototyping. Unlike horizontal prototypes used by Digital Innovators in crafting the service offering, System Integrators build vertical prototypes. These are minimal versions of the technical system which involve multiple layers or system components. This approach aims to gather feedback from a rough version of the system to evaluate technical design options and reduce risks that might be associated with technology choices. Such vertical prototypes help to evaluate technical options in real-world environments.

"I think we have tested six different [smart] glasses with customers and found out that: Phew, some of them are operated by voice, but it's too loud in the production environment, that didn't work, they're often made of glass, which can shatter, so broken glass in our production is a no-go. Then, some don't have any battery power that lasts for several hours [..], that is technically not possible." (PHARMACHINES, Head of Digital Solutions, 2020).

Since access to the field is not always available, organizations with the Project Sponsor role also work with their test scenarios to investigate the technical constraints for a potential solution at the target customer's site. Systems at this stage are aimed at an improved understanding of potential solutions and their parameters, but not for productive use.

"And now we have a machine in the laboratory where we can learn by ourselves. [..] We always do the whole thing under laboratory conditions. We don't have anything productive. I think that as soon as you transfer this to a productive operation, you might work a little differently. You have data engineers who develop everything in compliance with security requirements. 
Everything is still vulnerable to certain errors and attacks. It does not have the maturity level yet." (INTERNALIT, Project Manager, 2020)

As one of the key characteristics of smart service is data-driven value creation, it is not surprising that Systems Integrators also design data analytics. This theme includes the work of data scientists, who investigate the functional aspect, i.e., which data is needed to gain the desired result or which insights can be generated from available data. Here, we see a connection between the crafting of the smart service offering and the technical solution, as the potential value creation of a smart service is constrained by the available data. Consequently, Customer Representatives can be involved in the process.

"The customer is an important partner in the development of such projects because the customer carries the expert knowledge also for the analysis of the data. After all, this expert knowledge must ultimately also be incorporated into the data analyses." (INTERNALIT, Project Manager, 2020).

Data scientists work on the mathematical and statistical level of the problem and develop suitable data models and select appropriate methods for data analysis. Standards like CRISP-DM are applied to guide the iterative development of data mining models.

"This is an industry-standard, which is called crossindustry standard for Data Mining. This is applied by first understanding the companies, understanding the issues, then looking at what information we get. Afterward, pre-processing up to the development of the model and evaluating the whole thing. [..] If it is not good, then the loop starts all over again." (INTERNALIT, Data Scientist, 2020).

Moreover, data engineers are contributing to this by planning and setting up the infrastructure that collects, stores, and analyzes data according to the functional concept of the service system. This task is supported by state-of-theart tools, which allow graphical modeling of data analysis processes.

"Implementation then via orchestration frameworks, for example, Apache Nifi or Apache AirFlow. In the end, frameworks with which you orchestrate the whole process. So which data sources do I have? How do I import them? Where do I pass them on to? Where does the ETL take place? Do I pass it on to a third party?" (GLOBALSYS, IT Architect and Consultant, 2020).

Finally, we also consider building a production-grade system as a relevant theme. It involves steps like defining system components and their interfaces as well as the actual coding and testing. For that, established techniques like the Unified Modelling Language (UML) are used to develop, discuss, and communicate design decisions within the team. In addition, problems must be considered more holistically than in the prototyping phase to minimize technical uncertainty. This also raises the question of whether solutions should be purchased or developed in-house. Furthermore, we found that modern approaches like API management are used to define interfaces early and parallelize work even between different teams:

"Because the developers can store this API, that is, this Swagger API, in advance and can also tell which default values are returned. [..] This means that you can also code against this [interface] within an app, while the backend developers can develop the complex logic in the backend in parallel. That means you can decouple these two systems, even though they can pretend to talk to each other." (GLOBALSYS, IT Architect and Consultant, 2020).

"Of course, there is already a gap between the production department, which wants to have a problem solved quickly, and the IT department, which says that for me security is the highest priority. If production is not running, then production should first show me how high the loss is, because if we have a hacker attack, then I assume a loss of a few billion. They first have to make up for that with their production downtime." (PHARMACHINES, Product Manager for Service/Support, 2018).

Table 7 provides the themes, roles, and concepts for this aggregate dimension.

\section{Ensuring economic viability}

Developing value propositions that are attractive to target customers is a prerequisite for being successful in the marketplace. However, Project Sponsors also need to consider the capturing of value for themselves. The uncertainty related to this aspect is driven by difficult cost estimations for the smart service innovation project and operational costs during service provision, the unknown size of the target market, and the customers' readiness and willingness to pay for the new service offering.

Demonstrating customer value describes the theme which refers to activities aiming at market acceptance. Interviewees mentioned that such acceptance needs to be achieved by demonstrating the economic impact of pilot service deployments. Solving the customer's problem as promised leads to market acceptance and, thus, a customer's willingness to pay. But the same applies in the opposite direction. 
Table 7 Themes, roles, and concepts for "Developing a technical solution"

\begin{tabular}{|c|c|c|}
\hline Themes & Roles & Concepts \\
\hline Understanding the service idea & SI, PS & $\begin{array}{l}\text { - Elaborating a joint understanding of service idea } \\
\text { - Sharpening service concept Interactively }\end{array}$ \\
\hline Breaking down the problem & SI & $\begin{array}{l}\text { - Identifying solution-related risks } \\
\text { - Identifying main architectural building blocks }\end{array}$ \\
\hline Vertical prototyping & SI, PS, CR & $\begin{array}{l}\text { - Evaluating technical options in a real-world environment } \\
\text { - Assessing technical feasibility of solution architecture }\end{array}$ \\
\hline Designing data analytics & SI, PS, CR & $\begin{array}{l}\text { - Utilizing domain knowledge for the design of data analyses } \\
\text { - Developing suitable data models iteratively using process models } \\
\text { - Designing a technical infrastructure for orchestrating data analytics }\end{array}$ \\
\hline Building a production-grade system & SI & $\begin{array}{l}\text { - Utilizing modern approaches to allow for parallelization in development } \\
\text { - Designing and discussing system architecture within the development team } \\
\text { - Deciding on make-or-buy of system components }\end{array}$ \\
\hline
\end{tabular}

"If you promise a lower downtime or a lower standstill, you have to see if you really do what you promised in the end. If so, a corresponding willingness to pay arises, and you have to demonstrate the whole thing several times, prove that you can do it before you can scale the big one. Otherwise, you make empty promises and lose trust in the market. (INTERNALIT, Project Manager, 2020)

Our second round of interviews showed that the interviewees increasingly have to justify certain projects more thoroughly from a financial perspective to internal stakeholders. Hence, the theme establishing the business case subsumes such activities that justify smart service innovation projects. The interviewees try to select financially attractive customers right from the start. Whereas previously a lot of attention and effort was put into pilot projects and feasibility studies, as well as reactive measures to competitive pressures, there is now an increasing demand for economic project justification.

"Of course, we are currently entering a phase in which this business case view is becoming increasingly important, partly due to the organizational changes. And in this respect, I have already had to make classic business case calculations for projects." (INSURANCE, Project Manager, 2020)

"And that's why you generally have discussions right now about how to proceed with the projects at all (...) and then to clarify whether this is still worthwhile in terms of a return-on-investment." (GLOBALSYS, IT Architect and Consultant, 2020)

Even though financial considerations are becoming increasingly relevant, it is still common that organizations cross-subsidize service offerings through other sources of income. Project Sponsors justify smart service innovation through the generation of data that are valuable for their operational processes. In addition, organizations do not want to lose ground to competition and, even if projects fail economically, the interviewees described the learnings as beneficial for future endeavors.

"In the end, the company generates the added value. We have two problems. Their competitors have such a service in the market, and they want to keep up. And secondly, they profit when customers give them the data so that they can generate orders and do business again. And that is why they want to keep the hurdle so low." (GLOBALSYS, IT Architect and Consultant, 2018)

"At the car manufacturer, they know how important data is because they need to measure up to Tesla. Because Tesla has data, and that is the business model. They know that they have to get to market quickly. They have to exploit the data." (ENERGYTRADE, Program Manager, 2020)

Turning pilots into scalable offerings is the last theme that was often discussed in our interviews. Standardization, as well as the creation of platforms, were named as examples. Standardization describes the approach of reusing existing solutions and resources to minimize efforts and financial expenses. Another described action is the continuous validation of the customer's willingness to pay.

"For the MVP we also try to find three to five paying customers. If they don't pay, then we haven't solved the problem. The first customers, they might get it a bit cheaper, but then we work with these five customers (...) and when that's stable, then we add a few more customers and at some point, you're in a mode where you say: Okay, now it works with 20 customers, now it will work with 200 customers and then we pass it on." (PHARMACHINES, Head of Digital Solutions, 2020) 
The development of platforms or larger portfolios of smart service offerings is considered to lead to improved utilization of infrastructure investments.

"I don't think that any single service justifies all these implementation costs. [..] And if it only remains with one service, this project cannot be economical." (ITCONSULT, Program Manager, 2020)

However, many organizations still seem to be awaiting the scaling phase.

"How do you scale smart service? The challenge is that currently smart services are developed very, very individually [..] For a long time to come, it will remain purely a project business. That in the end, a product will emerge that can be scaled in a standardized way. That's still a dream of the future, it's very, very diffcult because each data model must be developed individually for each machine." (INTERNALIT, Project Manager, 2020)

Table 8 provides the themes, roles, and concepts for this aggregate dimension.

\section{Iterative uncertainty reduction in multi-actor smart service innovation}

The themes and dimensions that we derived from our interview data together with the assignment of roles illustrate that multiple actors have to accomplish many things and contribute various resources to establish a smart service system. To give some instances of how the actors engage with each other, we see that the Project Sponsor is involved in most activities and frequently collaborates with the Customer Representative and the Digital Innovator (Fig. 3). Actors with the System Integrator role tend to be responsible for most technical tasks, but also participate in various project management activities in multi-actor settings. The Digital Innovator role is usually involved in those activities that require interactions with Customer Representatives. All these activities can generally be shared between multiple roles. That is, actors can assume multiple roles, and a role can be assigned to several actors at the same time. This is particularly visible from bringing agile methods to life and ideating and designing solutions, where we assigned three roles. Ensuring economic viability also requires the Project Sponsor to collaborate with all other actors. In contrast, developing a technical solution is a theme that is rather exclusive to the System Integrator role. Therefore, the complexity of the multi-actor setup depends on the distribution of roles among concrete actors in the specific smart service innovation project and provides conditions for actor engagement during the actual project work.

The themes and dimensions further substantiate that uncertainty affects smart service innovation. For example, the crafting of a smart service offering is an innovation activity that is inherently affected by environmental uncertainty. The utilization of recent technology leads to technical uncertainty. Similarly, finding the right people with the right resources for the project on time, as well as coordinating their work was also perceived as a source of resource and relational uncertainty. Finally, the economic viability depends on decisions in all the previous areas as well as specific activities related to financial management. Moreover, strategic management decisions related to smart service innovation are likely to cause organizational uncertainty. Hence, smart service innovation is beset with uncertainty that stems from multiple sources. To manage uncertainty, a lot of the experts' attention was given to the agile ways of working together, which is characterized by an iterative and incremental approach to developing the different components of a smart service system.

Correspondingly, we interpret that it is iterative uncertainty reduction that drives the various actors to perform the activities in the way we learned from the interviews and, hence, we conceptualize it as our overarching core category. We refer to 'uncertainty reduction' and not to 'coping with

Table 8 Themes, roles, and concepts for "Ensuring economic viability"

\begin{tabular}{|c|c|c|}
\hline Activities & Roles & Concepts \\
\hline Demonstrating economic value & PS, DI, CR & $\begin{array}{l}\text { - Showing economic impact through initial service deployments } \\
\text { - Delivering what you promise to build market reputation }\end{array}$ \\
\hline Establishing the business case & PS, DI & $\begin{array}{l}\text { - Choosing problems with high revenue potential or savings potential } \\
\text { - Showing that the service offerings have a positive return-on-invest- } \\
\text { ment } \\
\text { - Reacting to competitive pressure }\end{array}$ \\
\hline Cross- Subsidizing & PS & $\begin{array}{l}\text { - Enabling data access or other strategic objectives } \\
\text { - Learning as a benefit even if projects fail economically }\end{array}$ \\
\hline Turning pilots into scalable offerings & PS, SI & $\begin{array}{l}\text { - Clarifying scaling opportunities and challenges } \\
\text { - Validating willingness to pay of pilot customers } \\
\text { - Identifying potentials for standardization and reusability }\end{array}$ \\
\hline
\end{tabular}




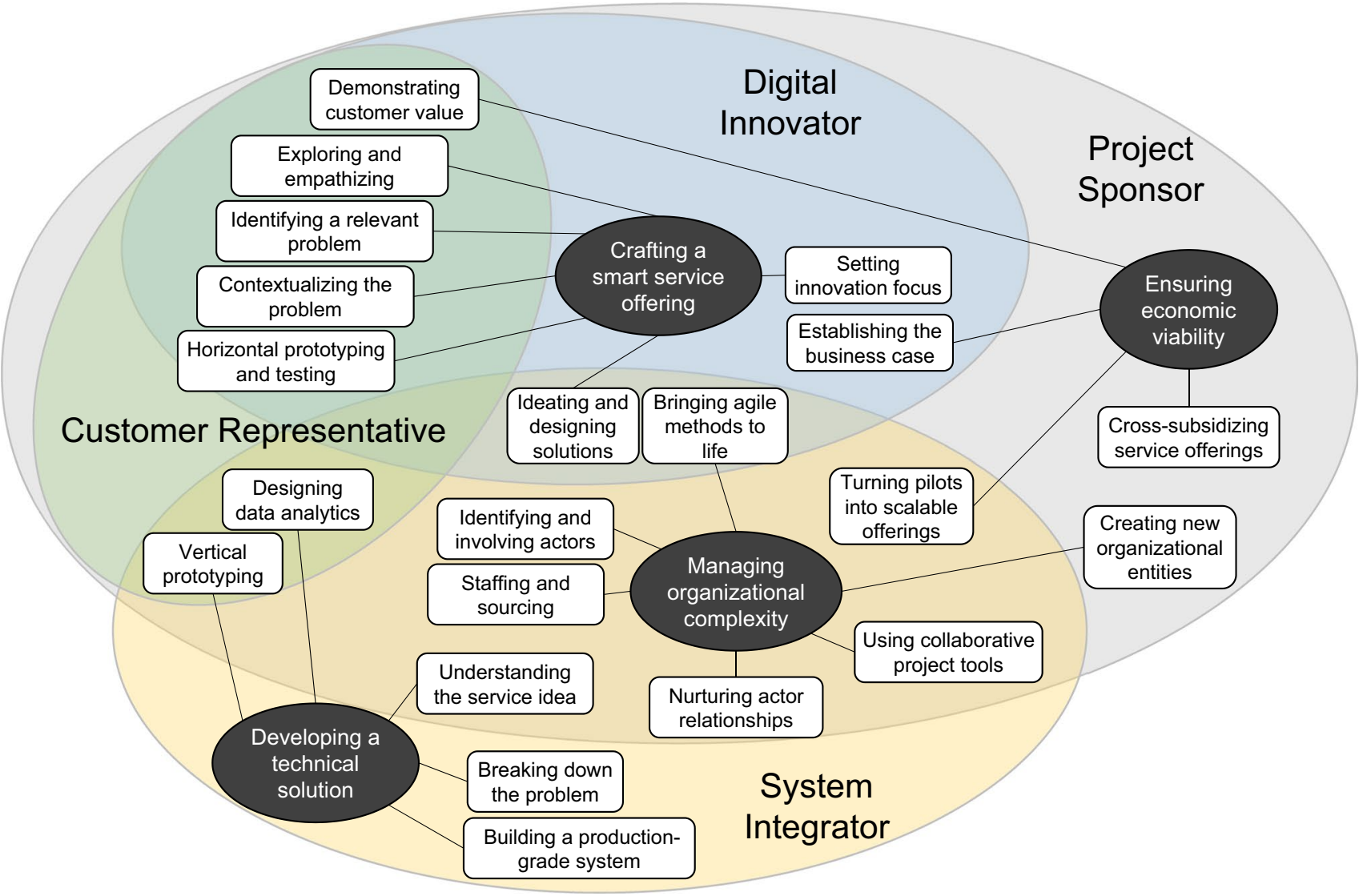

Fig. 3 Themes of smart service innovation assigned to roles

uncertainty' since our impression was that the multiple actors intend to reduce the different types of uncertainty of smart service innovation at their sources instead of just adapting to them (Simangunsong et al., 2012). We deliberately add the term 'iterative' to 'uncertainty reduction' because the activities across all dimensions indicate that the interviewees choose or recommend iterative approaches in response to uncertainty. When following an iterative approach to uncertainty reduction, innovation activities are carried out, their outcome is put to the test, and adjustments can be made quickly. An iterative approach was perceived to support customer involvement and regular feedback on the emerging solutions.

When making sense of iterative uncertainty reduction as our core category, we further realized that uncertainty is a property on a higher level of aggregation compared to the actors' activities as it refers to the collection of multiple actors that engage with each other during smart service innovation. The aforementioned uncertainty types mainly relate to the multi-actor nature of smart service innovation (pointing towards, e.g., resource and relational uncertainty) where the outcome in terms of changes to the smart service system (pointing towards, e.g., technical, organizational, and environmental uncertainty) is difficult to predict. Following the framework by Storbacka et al. (2016), we therefore conceptualize smart service innovation uncertainty as a property of the meso-level (Fig. 4), which refers to both the actor-to-actor network with a joint smart service innovation project as the engagement platform, and the smart service system with its changed resource integration patterns as the outcome of smart service innovation. In light of the existing conditions of uncertainty relevant to a project, the involved actors perform activities generating a new configuration of resources which is usually supposed to reduce uncertainty. Adding a microfoundational view to this meso-level relationship, the project set-up provides the conditions for actor engagement on the micro-level during project work (situational mechanism). We understand the intentions and the roles that the actors enact during project work as actor dispositions that are turned into action in the specific project context (action-formation mechanism). The concepts, themes, and dimensions of activities, which we presented above, reflect the engagement properties, which are the observable engagement activities on the micro-level (Storbacka et al., 2016). The collective action of all actors leads to the 


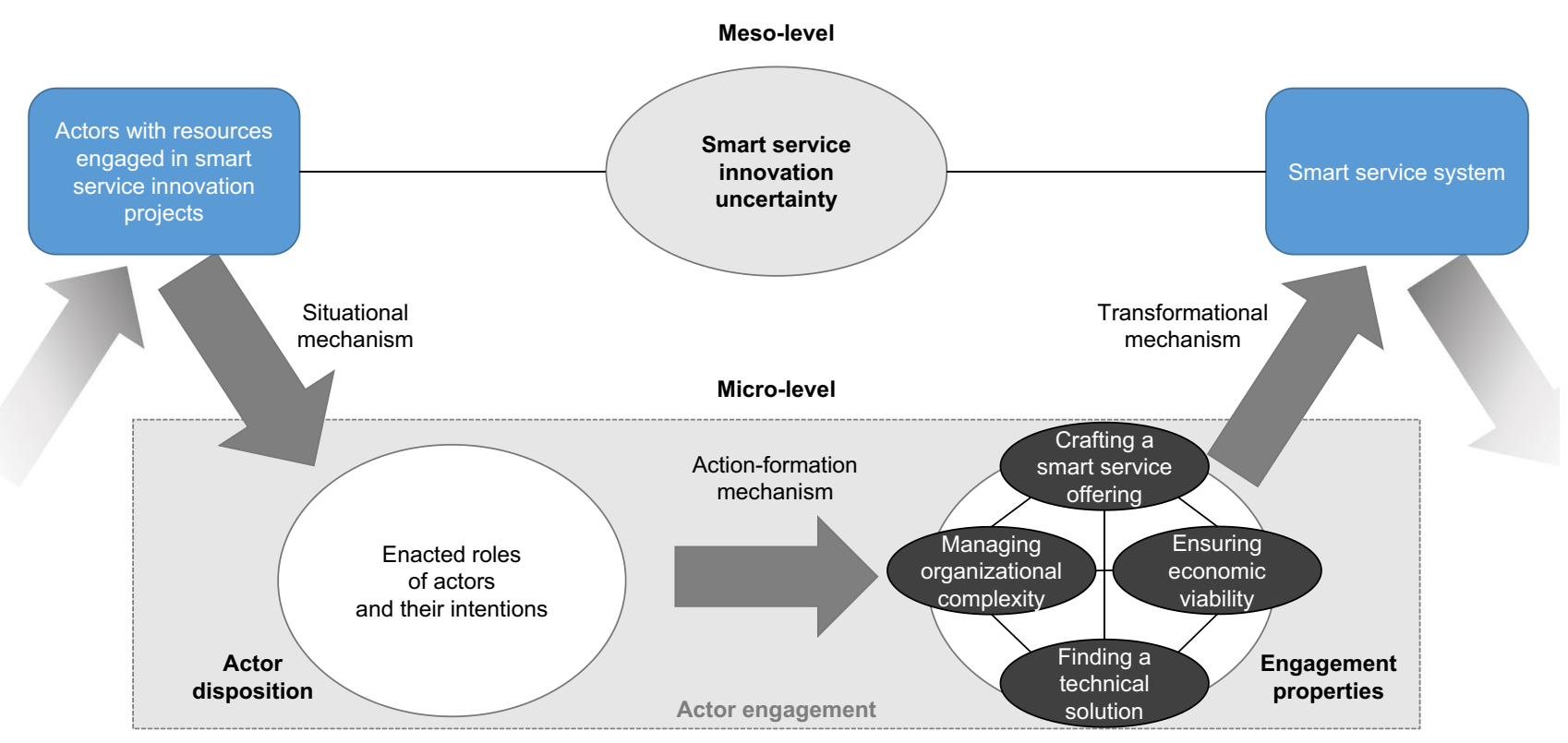

Fig. 4 Theoretical model of iterative uncertainty reduction in smart service innovation

emergence of a new smart service system or changes to an existing smart service system (transformational mechanism), which can, in turn, be the outset of future innovation processes (as reflected by the fading arrows in Fig. 4).

The theoretical model resembles that the engagement properties that we derived from our data analysis are interdependent. For example, involving users as part of exploring and empathizing causes additional multi-actor complexity that needs to be managed. Similarly, the design of a certain technical solution requires specialists that must be involved in the project but also influences the economic viability of the overall service system. Furthermore, the technical solutions are dependent on the service offering to be delivered. The interdependencies are not limited to the micro-level, but also constantly affect the actor-to-actor network on the meso-level and, hence, the smart service innovation uncertainty as a property of that level.

\section{Discussion}

\section{Theoretical contributions}

With our grounded-theory-based interpretative study, we make contributions to the empirical inquiry of smart service innovation in multi-actor settings. We developed a theoretical model that is grounded in the data of 25 interviews with experts, who were involved in multi-actor smart service innovation. Our model draws on the framework by Storbacka et al. (2016) and thereby provides a multilevel perspective on iterative uncertainty reduction in smart service innovation. We specifically focus on the micro- and meso-level of the framework and describe how actor engagement in collaborative innovation activities on the micro-level relate to the smart service system on the meso-level. We identified four aggregate dimensions of activities including (1) managing multi-actor complexity, (2) crafting a smart service offering, (3) developing a technical solution, and (4) ensuring economic viability. We found that these activities are carried out by the involved actors under conditions of uncertainty resulting in iterative uncertainty reduction, affecting the smart service system as the innovation outcome. This study yields multiple contributions to the academic discourse on smart service innovation as described in the following.

First, we answer recent calls for more theoretical and empirical research on smart service systems (Djellal \& Gallouj, 2018), especially considering broader sets of ecosystem actors that shape value creation in times of digital transformation (Sjödin et al., 2020b; Vink et al., 2021). Our findings emphasize that smart service innovation requires the collaboration of several actors who contribute a wide range of resources (Beverungen et al., 2018; Edvardsson et al., 2018; Lusch \& Nambisan, 2015). With our study, we also address the need for evidence-based research on S-D logic that is "more midrange and microlevel theoretical in nature [...]." as put forward by Vargo and Lusch (2017, p. 50). In particular, our empirical insights shed light on the research frontier that they see concerning the co-creation of strategic planning and implementation by multiple stakeholders and how this co-creation affects firms and their stakeholders (Vargo \& Lusch, 2017). In this regard, our findings indicate that smart 
service innovation projects can be considered as engagement platforms that provide shared institutional arrangements and facilitate the co-creation of strategic innovation initiatives. We identified iterative uncertainty reduction as our core category that reflects how co-creation in smart service innovation affects the actors involved. Moreover, we utilized the framework by Storbacka et al. (2016) to develop our multilevel theoretical model of iterative uncertainty reduction in smart service innovation, which is grounded in empirically observed activities (as reflected by the concepts, themes, and dimensions). Thus, we support ambitions leading to additional midrange and micro-level theory development that can help bridge the gap between S-D Logic as meta-theory and real-life practice (Vargo \& Lusch, 2017).

Taking a broader view, we also contribute to a better understanding of microfoundations in the context of digital transformation, which has been identified as an open research issue (Vial, 2019), too. Our grounding in S-D logic could provide a fresh perspective on how digital transformation can lead to changes in resource integration patterns and value creation. Parts of our theoretical model could be applicable to other settings of digital transformation beyond smart service innovation, which needs to be investigated further in future empirical studies. With regard to research on microfoundations in related fields, other works have previously conceptualized microfoundations of service innovation (Kindström et al., 2013) and digital transformation (Warner \& Wäger, 2019) capabilities. These works, however, basically follow an understanding of microfoundations as subcapabilities (Warner \& Wäger, 2019) of organizational dynamic capabilities in line with Teece (2007). Hence, these works look at different levels of abstraction of capabilities (of a single organization), but do not consider different levels of aggregation (e.g., actors, service systems, and service ecosystems) as we do in this study based on the framework provided by Storbacka et al. (2016), which helped us to conceptualize the multi-actor nature of smart service innovation with its relevant facets.

Second, our study adds another level of detail to our understanding of smart service innovation by investigating activities at the micro-level of actor engagement (Storbacka et al., 2016). Thus, we go beyond existing studies that remain on macro- and meso-levels (e.g., Anke et al., 2020c; Ekman et al., 2016). Precisely, our findings illustrate what different actors actually do when they innovate collaboratively and how these activities provide microfoundations for managing uncertainty in smart service innovation. Our data structure with 54 concepts, 21 themes, and four aggregate dimensions gives a detailed and empirically grounded account of smart service innovation that was not available in previous studies. Furthermore, we provide linkages between the micro-level and the meso-level through our mapping of activities and actors' roles (Anke et al., 2020c). Adopting the concepts that Grotherr et al. (2018) use, we can say that our previous study (Anke et al., 2020c) has focused on the institutional design cycle that connects the macro- and the meso-level, whereas this study provides additional empirical insights into the engagement design cycle that links the meso- and the micro-level. Thereby, our previous (Anke et al., 2020c) and this study viewed together can provide a holistic understanding of smart service innovation across all levels that the framework of Storbacka et al. (2016) defines, from the macro-perspective of service ecosystems to actor engagement during operational project work.

Third, our results contribute to a better understanding of what makes methodologies suitable for collaborative projects that intend to develop socio-technical systems. Our interviewees mostly recommended the use of agile methodologies from software engineering like Scrum. These methodologies put a focus on short development cycles and continuous involvement of customers to enable the joint exploration of the customer problem and the iterative development of a suitable solution. Basic ideas of such agile approaches have also been integrated into SSE methodologies (Beverungen et al., 2018; DIN, 2019; Jussen et al., 2019; Usländer \& Batz, 2018), too. However, they do not consider the involvement of multiple actors (beyond the customer) yet, and therefore do not guide how a network of actors can collaborate effectively during smart service innovation projects. To address this blind spot of existing SSE methodologies, it is conceivable to consider other, but more complex process models from software engineering like the Rational Unified Process (Kruchten, 2004) and the German 'V-Modell XT' (Angermeier et al., 2019) because these have been specifically developed to address multi-actor collaboration in large software development projects. However, the interviewees also emphasized that a flexible choice of easy-to-use methods for tasks at hand is required to cater for the explorative characteristic of smart service innovation, which would contradict the use of too formal and complex methodologies.

Fourth, by identifying iterative uncertainty reduction as the core category underlying our theoretical framework, our study links the two separate research streams of innovation uncertainty (e.g., Jalonen, 2012; O'Connor \& Rice, 2013), and smart service innovation (Anke et al., 2020c; Beverungen et al., 2018). On the one hand, literature on the development of smart service systems, although recognizing them as "complex, open, and dynamic sociotechnical systems" (Beverungen et al., 2019a, p. 1202), has rarely touched upon the phenomenon of uncertainty. SSE methodologies and procedure models for smart service innovation (Beverungen et al., 2018; Jussen et al., 2019) consider uncertainty only implicitly when they recommend agile approaches, which are generally expected to help actors in accommodating and 
adapting to unforeseen changes in dynamic environments (Sjödin et al., 2020b). Our empirical findings provide a better understanding of why agile process models are particularly suitable for smart service innovation. The attribute iterative of our core category supports this basic idea of dealing with uncertainty.

In contrast, uncertainty has been discussed in innovation research intensively (Beynon et al., 2020; Jalonen, 2012; O'Connor \& Rice, 2013), and a few times even in specific relation to (1) service innovation, (2) multi-actor settings, (3) digital transformation or combinations thereof (Ndubisi et al., 2020; Ortiz de Guinea \& Raymond, 2019; Ramirez Hernandez \& Kreye, 2021). Our empirical findings indicate that all of these three characteristics of multi-actor smart service innovation require activities directed towards reducing uncertainty. Ad (1), service innovation is usually linked to environmental uncertainty as customers' needs, preferences, and demands may not be well understood or can change unpredictably (Ndubisi et al., 2020). For product-oriented firms, service innovation is also likely to cause organizational uncertainty on their servitization journey, e.g., in relation to pricing and reorganization decisions or due to a lack of service culture (Ramirez Hernandez \& Kreye, 2021; Sklyar et al., 2019). Ad (2), multi-actor settings fuel relational uncertainty, while, at the same time, they can reduce resource uncertainty by making specialized knowledge and technical resources of other actors available (Ramirez Hernandez Kreye 2021). Ad (3), the context of digital transformation can lead to technical uncertainty in manifold ways because of the fast development of digital technologies, the increasing number of interfaces between smart products, digital devices, and legacy systems (Ramirez Hernandez \& Kreye, 2021), as well as the increasing influence of consumers on trends related to the use of digital technologies (Vial, 2019).

Our empirical findings mirror all these uncertainty types and emphasize that they need to be addressed holistically in smart service innovation. Through our data analysis, we were able to uncover the activities that the actors enact simultaneously to reduce these various influences of uncertainty in their smart service innovation processes. For instance, exploring and emphasizing as well as horizontal prototyping and testing support the reduction of environmental uncertainty, whereas vertical prototyping helps manage technical uncertainty. Mapping the aggregate dimensions of our theoretical model with the uncertainty types, we see that managing multi-actor complexity mainly addresses resource, organizational and relational uncertainty; crafting a service offering mainly considers environmental uncertainty, especially in terms of customer understanding; developing a technical solution covers the management of technical uncertainty; and ensuring economic viability is directed towards organizational and environmental uncertainty with regards to the wider business context of competitors, suppliers and larger macro-developments in the industry (Ramirez Hernandez \& Kreye, 2021). Furthermore, the four aggregate dimensions are not independent. The multi-actor setting of smart service innovation inherently causes uncertainty reallocation as described by Ramirez Hernandez and Kreye (2021). On the one hand, the interdependent actors provide access to and recombine each other's resources (Beverungen et al., 2019b), thus reducing resource uncertainty. On the other hand, this leads to increased relational uncertainty, which requires the management of multi-actor complexity.

Our insights from the two rounds of interviews also indicate that the strategies of managing uncertainty, and, hence the relative importance of aggregate dimensions to different actors, might change over time, both during a single project and in the long term. In particular, ensuring a smart service system's economic viability has become a pressing challenge. Our experts reported that there was an increasing expectation to establish business cases for smart service innovation, while they had often been considered strategic investments or exploration projects without such a financial assessment only a few years ago. This might indicate a move from just coping or even accepting environmental uncertainty towards uncertainty reduction in its actual sense.

\section{Limitations}

As with all exploratory research, this study is not without limitations. Our data structure and theoretical model are grounded in the qualitative-empirical data of 25 interviews with informants from 13 organizations only. Although we felt to have achieved theoretical saturation with this set of interviews, investigating additional examples of smart service innovation processes as well as interviewing informants from other types of actors (e.g., customer organizations) could have led us to different conceptualizations. Another limitation concerns the limited perspective that we gathered on the activities of organizational actors because we interviewed only one expert per organization in most cases. The two deviant cases are PHARMACHINES and INTERNALIT, where the initial respondents from 2018 had left the organization by our second round of interviews in 2020 . On the one hand, this inhibited a consistent perspective across the two rounds of interviews and forced us to search for alternative informants. This, however, even led to multiple respondents in 2020, and, hence, to a more comprehensive view on their smart service innovation processes, which we did not achieve for the other organizations. Furthermore, our codings and conceptualizations resulted from subjective interpretations of the interview data. We did not strive for any reliability of our codings. Instead, all three researchers engaged in a joint sensemaking process that aimed at a 
consensual understanding that offers meaningful descriptions and explanations for the phenomenon under study. All the aforementioned limitations might also restrict the transferability of our theoretical model into a wider research context, e.g., digital transformation or radical innovation projects more generally. Finally, the aggregate dimensions and concepts from our data structure should not be considered as normative advice on what good or best practices are. Based on the interview data, it is difficult to make a statement about the success of those activities because we were not able to assess innovation performance.

\section{Practical implications}

For practitioners, our results are relevant regarding (1) the staffing and management of projects in multi-actor settings, (2) agile methods as key enablers for service innovation, and

(3) developing economically viable service offerings.

First, our dimensions, themes, and concepts describe what the different actors typically do when they engage in collaborative smart service innovation. In this sense, they can provide a basic idea about the necessary resources, skills, and processes for smart service innovation. This does not only provide guidance for setting up and conducting such initiatives but also highlights potential dependencies on other actors. As smart service innovation takes place in multi-actor settings, it is key to identify and maintain relationships with relevant partners that complement the resources of one's organization. From a more strategic perspective, the different actors (e.g., the service provider) need to decide which of the required resources they want to build up internally and which ones are to be sourced externally. Our findings show which activities are usually taken over by which role and can thereby serve as a guideline for sourcing decisions. During data analysis, we assigned the activities to multiple roles. This indicates the necessity to collaborate with others unless a single actor assumes all relevant roles itself, which reduces complexity due to less cross-organizational coordination.

Second, the identified core category of iterative uncertainty reduction emphasizes the importance of an iterative process for smart service innovation. While it has to be acknowledged that uncertainty is an inherent part of any innovation, the awareness of the various sources of uncertainty as well as possible approaches to handling them may improve the innovation process (Jalonen 2012). The experts consistently recommend the use of agile methodologies to gradually reduce uncertainty. They also expect that following agile methodologies increases the likelihood that new smart service offerings are designed in a way that they meet actual customer demands. Nevertheless, agile methodologies also come with certain obligations for customers, e.g., the active participation in the role of a product owner during the project.

Third, as it cannot be overstated that smart service offerings need to solve a relevant problem of a customer, it makes sense to follow customer-centric approaches. Practice-oriented literature on business model innovation describes a continuous testing and experimentation process that distinguishes between desirability, feasibility, and viability in the progress of scaling business ideas (Bland \& Osterwalder, 2019; Osterwalder et al., 2020). As progress is made, the focus shifts more towards assessing and ensuring viability. Hence, it is important to keep a balance of customer needs, technical feasibility, and provider value when crafting a service offering as reflected by our set of aggregate dimensions. That is, looking at crafting a smart service offering in isolation only addresses the issue of 'desirability'. This theme needs to be combined with assessing feasibility, to avoid putting a lot of effort into service ideas that cannot be realized in the end. If services are built from a technical perspective (developing a technical solution) without involving the customer, the Project Sponsor risks creating a service offering that fails to address customer needs. In the end, ensuring economic viability is needed to ensure that costs for building and operating the smart service systems are exceeded by benefits at the provider, which can take the form of revenue, savings, or strategic benefit (Zolnowski et al., 2017). Likely, the basic digital infrastructure that needs to be built up before any smart service can be offered is very costly due to its technical complexity. Therefore, practitioners should think ahead in how far their investments can lead to platforms, standardized components, or even white-label solutions that can be reused at a larger scale. Alternatively, it might make sense to incrementally build up micro-services as Sjödin et al. (2020b) suggest.

\section{Conclusions and outlook}

In this qualitative-empirical interview study, we examined how multiple actors collaborate in smart service innovation. Drawing on the theoretical lens of microfoundations (Felin et al., 2015; Haack et al., 2019) and the framework by Storbacka et al. (2016), we went beyond existing studies that remain on macro- and meso-level perspectives (Anke et al., 2020c; Ekman et al., 2016; Grotherr et al., 2018; Storbacka et al., 2016) and looked at the actor engagement on the micro-level in particular. Grounded in our interview data, we conceptualized four aggregate dimensions of actor activities, which are (1) managing multi-actor complexity, (2) crafting a smart service offering, (3) finding a technical solution, and (4) ensuring economic viability. We mapped the activities to the roles as conceptualized by Anke et al. (2020c), thereby 
providing a connection to the actor-to- actor network on the meso-level. We further conceptualized iterative uncertainty reduction as the core category underlying our theoretical model. Our findings explain how the activities of actors on the micro-level influence the environmental, technical, organizational, resource, and relational uncertainty (Ramirez Hernandez \& Kreye, 2021) as a meso-level property of multi-actor smart service innovation.

Future research should try to understand the specific sources of uncertainty in smart service innovation processes better. From our interview data, we were able to derive that the actors were inherently confronted with manifold types of uncertainty, but they hardly named them explicitly. Future qualitative interview studies should dig deeper here, putting the interviewees' perceptions of uncertainty center stage and relating them to further aspects that might be relevant to smart service innovation success, like developing a service culture, a customer-centric culture, or a digital mindset within organizations (Kindström et al., 2013; Ramirez Hernandez \& Kreye, 2021; Warner \& Wäger, 2019). In this regard, it could also make sense to explicitly study innovation failures. Such perspectives would probably also shed additional light on the various paradoxes that organizations have to cope with in today's dynamic environments (Gebauer et al., 2005; Kohtamäki et al., 2020; Sjödin et al., 2020b), like, e.g., the implementation of a customer orientation while maintaining an engineering mindset. Apart from these suggestions for further small-sample and qualitative studies, large-N survey studies could provide a further promising avenue for advancing microfoundational research (Foss, 2016). Here, the diverse existing conceptualizations of microfoundations and capabilities for service innovation and digital transformation (e.g., den Hertog et al., 2010; Kindström et al., 2013; Plattfaut et al., 2015; Warner \& Wäger, 2019) could be put to the test in how far they can explain dependent variables like innovation performance or corporate success.

Future research should also try to investigate the engagement properties of the activities that can be observed in smart service innovation more thoroughly (Storbacka et al. 2016). Our findings already indicate that most, but perhaps not all, of the activities (as reflected by the concepts, themes, and dimensions of our data structure) require the mutual contribution of resources by multiple actors and hence can be classified as 'co-production activities' rather than 'value-in-use activities', which would be independent from the providing actor's presence (Storbacka et al., 2016, p. 6). Further issues relate to the information, relational, and temporal engagement properties of actor engagement (Storbacka et al., 2016). Regarding temporal properties, for instance, we can conclude from our previous research that actors may join or leave the smart service innovation project as the required resources also change over time (Anke et al., 2020c).
Finally, our findings might also spark design science research projects that advance the development of methodologies for smart service innovation and digital transformation (Alt, 2019; Anke et al., 2020a). In particular, the two aspects of multi-actor settings and uncertainty reduction could be considered as blind spots of existing methodologies. Our findings support that the agile and iterative outlines of recent process models for smart service innovation (Beverungen et al., 2018; DIN, 2019; Jussen et al., 2019), which appear to be borrowed from software engineering, are meaningful and appear to be compatible with common practices of our interviewees, at least on an abstract level. However, it also became apparent from the interviews that the experts from practice usually do not know smart service-specific process models and methods that have been suggested in academia. Involving practitioners in such developments might also simplify the transfer of these methodologies into practice. One further approach may also be the adaptation of rather complex agile frameworks from software engineering like the Scaled Agile Framework (Scaled Agile Inc., 2020) or Disciplined Agile (PMI, 2020) to smart service innovation. Here it could make sense to map our dimensions, themes, and roles to the practices and roles as described in these agile frameworks.

Another important aspect with regard to methodologies is to find a suitable level of flexibility for the choice of methods and techniques. Due to the variety of aspects to be considered in the development of smart service systems, methods from different disciplines can generally be employed. As recent research has shown, different types of methods can be flexibly combined to effectively guide practitioners within an innovation process for digital services (Sjödin et al., 2020b; Anke et al., 2020a; Richter \& Anke, 2021). Future studies should work towards an inventory of existing methods, which are suitable for smart service innovation, ideally based on empirical evaluation. A step towards such an inventory can be seen in the method compendium proposed by Holler et al. (2018), which contains methods for usercentric innovation, prototyping, as well as system, service and business modeling. Moving further towards this direction would help academics to develop methods and tools that address practical design problems in multi-actor smart service innovation.

Funding Open Access funding enabled and organized by Projekt DEAL.

Open Access This article is licensed under a Creative Commons Attribution 4.0 International License, which permits use, sharing, adaptation, distribution and reproduction in any medium or format, as long as you give appropriate credit to the original author(s) and the source, provide a link to the Creative Commons licence, and indicate if changes were made. The images or other third party material in this article are included in the article's Creative Commons licence, unless indicated otherwise in a credit line to the material. If material is not included in 
the article's Creative Commons licence and your intended use is not permitted by statutory regulation or exceeds the permitted use, you will need to obtain permission directly from the copyright holder. To view a copy of this licence, visit http://creativecommons.org/licenses/by/4.0/.

\section{References}

Abrell, T., Pihlajamaa, M., Kanto, L., vom Brocke, J., \& Uebernickel, F. (2016). The role of users and customers in digital innovation: Insights from B2B manufacturing firms. Information \& Management, 53(3), 324-335. https://doi.org/10.1016/j.im.2015.12.005 acatech. (2015). Smart service welt: Recommendations for the strategic initiative web-based services for businesses. Final report. acatech - National Academy of Science and Engineering. https://en. acatech.de/publication/recommendations-for-the-strategic-initi ative-web-based-services-for-businesses-final-report-of-thesmart-service-working-group/

Alt, R. (2019). Electronic markets on digital transformation methodologies. Electronic Markets, 29(3), 307-313. https://doi.org/10. 1007/s12525-019-00370-x

Angermeier, D., Bartelt, C., Bauer, O., Beneken, G., Bergner, K., Birowicz, U., Bliß, T., Breitenstrom, C., Cordes, N., Cruz, D., Dohrmann, P., Friedrich, J., Gnatz, M., Hammerschall, U., Hidvegi-Barstorfer, I., Hummel, H., Israel, D., Klingenberg, T., Klugseder, K., ... Wittmann, M. (2019). V-Modell XT (Weit e.V., Ed.). http://ftp.tu-clausthal.de/pub/institute/informatik/vmodell-xt/Releases/2.3/Dokumentation/V-Modell-XT-HTML/ index.html

Anke, J., Ebel, M., Poeppelbuss, J., \& Alt, R. (2020a). How to tame the Tiger-exploring the means, ends and challenges in smart service systems engineering. European Conference on Information Systems (ECIS). https://aisel.aisnet.org/ecis2020_rp/155

Anke, J., Poeppelbuss, J., \& Alt, R. (2020b). Joining forces: Understanding organizational roles in inter- organizational smart service systems engineering. 15th International Conference on Wirtschaftsinformatik (WI 2020), Potsdam, Germany. http://dx. doi.org/10.30844/wi_2020_j1-anke

Anke, J., Poeppelbuss, J., \& Alt, R. (2020c). It takes more than two to tango: identifying roles and patterns in multi-actor smart service innovation. Schmalenbach Business Review, 72(4), 599-634. https://doi.org/10.1007/s41464-020-00101-2

Barrett, M., Davidson, E., Prabhu, J., \& Vargo, S. L. (2015). Service innovation in the digital age: Key contributions and future directions. MIS Quarterly, 39(1), 135-154.

Beverungen, D., Breidbach, C. F., Poeppelbuss, J., \& Tuunainen, V. K. (2019a). Smart service systems: An interdisciplinary perspective. Information Systems Journal, 29(6), 1201-1206. https://doi.org/ 10.1111/isj. 12275

Beverungen, D., Lüttenberg, H., \& Wolf, V. (2018). Recombinant Service Systems Engineering. Business \& Information Systems Engineering, 60(5), 377-391. https://doi.org/10.1007/ s12599-018-0526-4

Beverungen, D., Müller, O., Matzner, M., Mendling, J., \& vom Brocke, J. (2019b). Conceptualizing smart service systems. Electronic Markets, 29(1), 7-18. https://doi.org/10.1007/ s12525-017-0270-5

Beynon, M. J., Jones, P., \& Pickernell, D. (2020). SME development strategy and product/service innovation intention: A NCaRBS analysis of the role of uncertainty. The International Journal of Entrepreneurship and Innovation, 21(1), 3-16. https://doi.org/ $10.1177 / 1465750318807401$

Bland, D. J., \& Osterwalder, A. (2019). Testing business ideas: A field guide for rapid experimentation. John Wiley \& Sons.
Böhmann, T., Leimeister, J. M., \& Möslein, K. (2014). Service systems engineering. Business \& Information Systems Engineering, 6(2), 73-79. https://doi.org/10.1007/s12599-014-0314-8

Breidbach, C., \& Maglio, P. (2015). A service science perspective on the role of ICT in service innovation. European Conference on Information Systems (ECIS) Research-in-Progress Papers. https://aisel.aisnet.org/ecis2015_rip/33

Chowdhury, S., Haftor, D., \& Pashkevich, N. (2018). Smart productservice systems (Smart PSS) in industrial firms: A literature review. Procedia CIRP, 73, 26-31. https://doi.org/10.1016/j. procir.2018.03.333

Coreynen, W., Matthyssens, P., \& Van Bockhaven, W. (2017). Boosting servitization through digitization: Pathways and dynamic resource configurations for manufacturers. Industrial Marketing Management, 60, 42-53. https://doi.org/10.1016/j.indmarman. 2016.04.012

de Jong, J. P. J., \& Vermeulen, P. A. M. (2003). Organizing successful new service development: A literature review. Management Decision, 41(9), 844-858. https://doi.org/10.1108/0025174031 0491706

den Hertog, P., van der Aa, W., \& de Jong, M. W. (2010). Capabilities for managing service innovation: Towards a conceptual framework. Journal of Service Management.

DIN. (2019). DIN SPEC 33453:2019-09, Entwicklung digitaler Dienstleistungssysteme. Beuth Verlag GmbH. https://doi.org/10. 31030/3085072

Djellal, F., \& Gallouj, F. (2018). Fifteen challenges for service innovation studies. In F. Djellal, \& F. Gallouj (Eds.), A Research Agenda for Service Innovation (pp. 1-26). Edward Elgar Publishing. https://doi.org/10.4337/9781786433459.00005

Edvardsson, B., \& Tronvoll, B. (2013). A new conceptualization of service innovation grounded in S-D logic and service systems. International Journal of Quality and Service Sciences, 5(1), 19-31. https://doi.org/10.1108/17566691311316220

Edvardsson, B., Tronvoll, B., \& Witell, L. (2018). An ecosystem perspective on service innovation. In F. Djellal, \& F. Gallouj (Eds.), A Research Agenda for Service Innovation (pp. 85-102). Edward Elgar Publishing. https://www.elgaronline.com/view/edcoll/ 9781786433442/9781786433442.00009.xml

Eisenhardt, K. M. (1989). Building theories from case study research. The Academy of Management Review, 14(4), 532-550. https:// doi.org/10.2307/258557

Ekman, P., Raggio, R. D., \& Thompson, S. M. (2016). Service network value co-creation: Defining the roles of the generic actor. Industrial Marketing Management, 56, 51-62. https://doi.org/10. 1016/j.indmarman.2016.03.002

Felin, T., Foss, N. J., \& Ployhart, R. E. (2015). The microfoundations movement in strategy and organization theory. Academy of Management Annals, 9(1), 575-632. https://doi.org/10.5465/19416 520.2015.1007651

Floerecke, S., Lehner, F., \& Schweikl, S. (2020). Cloud computing ecosystem model: Evaluation and role clusters. Electronic Markets. https://doi.org/10.1007/s12525-020-00419-2

Foss, N. J. (2016). Reflections on a decade of microfoundations research. Revista de Administração, 51(1), 117-120. https://doi. org/10.5700/rausp1227

Gebauer, H., Fleisch, E., \& Friedli, T. (2005). Overcoming the service paradox in manufacturing companies. European Management Journal, 23(1), 14-26. https://doi.org/10.1016/j.emj.2004.12.006

Gehman, J., Glaser, V. L., Eisenhardt, K. M., Gioia, D., Langley, A., \& Corley, K. G. (2018). Finding theory-method fit: A comparison of three qualitative approaches to theory building. Journal of Management Inquiry, 27(3), 284-300. https://doi.org/10.1177/ 1056492617706029 
Gioia, D. (2021). A systematic methodology for doing qualitative research. The Journal of Applied Behavioral Science, 57(1), 20-29. https://doi.org/10.1177/0021886320982715

Gioia, D., Corley, K. G., \& Hamilton, A. L. (2013). Seeking qualitative rigor in inductive research: Notes on the Gioia methodology. Organizational Research Methods, 16(1), 15-31. https://doi.org/ 10.1177/1094428112452151

Grotherr, C., Semmann, M., \& Böhmann, T. (2018). Using microfoundations of value co- creation to guide service systems design-a multilevel design framework. Proceedings of the 39th International Conference on Information Systems (ICIS). https://aisel. aisnet.org/icis2018/service/Presentations/8

Haack, P., Sieweke, J., \& Wessel, L. (2019). Microfoundations and multi-level research on institutions. In P. Haack, J. Sieweke, \& L. Wessel (Eds.), Microfoundations of institutions (pp.11-40). Emerald Publishing Limited.

Hallberg, L. R.-M. (2006). The "core category" of grounded theory: Making constant comparisons. International Journal of Qualitative Studies on Health and Well-Being, 1(3), 141-148. https://doi. org/10.1080/17482620600858399

Hedström, P., \& Swedberg, R. (1998). Social mechanisms: An analytical approach to social theory. Cambridge University Press.

Herterich, M., Uebernickel, F., \& Brenner, W. (2015). The impact of cyber-physical systems on industrial services in manufacturing. Procedia CIRP, 30, 323-328. https://doi.org/10.1016/j.procir. 2015.02.110

Höckmayr, B., \& Roth, A. (2017). Design of a method for service systems engineering in the digital age. Proceedings of the 38th International Conference on Information Systems (ICIS), Seoul.

Holler, M., Herterich, M., Dremel, C., Uebernickel, F., \& Brenner, W. (2018). Towards a method compendium for the development of digitized products-findings from a case study. International Journal of Product Lifecycle Management. https://doi.org/10. 1504/ijplm.2018.092825

Hurst, P. (1982). Ideas into action development and the acceptance of innovations. International Journal of Educational Development, 1(3), 79-102. https://doi.org/10.1016/0738-0593(82) 90046-3

Husnjak, S., Peraković, D., Forenbacher, I., \& Mumdziev, M. (2015). Telematics system in usage based motor insurance. Procedia Engineering, 100, 816-825. https://doi.org/10.1016/j.proeng. 2015.01 .436

Jalonen, H. (2012). The Uncertainty of Innovation: A Systematic Review of the Literature. Journal of Management Research, 4(1), 54.

Jonas, J. M., Boha, J., Sörhammar, D., \& Moeslein, K. M. (2018). Stakeholder engagement in intra-and inter-organizational innovation: Exploring antecedents of engagement in service ecosystems. Journal of Service Management, 29(3), 399-421. https:// doi.org/10.1108/JOSM-09-2016-0239

Jussen, P., Kuntz, J., Senderek, R., \& Moser, B. (2019). Smart service engineering. Procedia CIRP, 83, 384-388. https://doi.org/10. 1016/j.procir.2019.04.089

Kambil, A., \& Short, J. E. (1994). Electronic integration and business network redesign: A roles-linkage perspective. Journal of Management Information Systems, 10, 59-84. https://doi.org/10. 1080/07421222.1994.11518020

Kindström, D., Kowalkowski, C., \& Sandberg, E. (2013). Enabling service innovation: A dynamic capabilities approach. Journal of Business Research, 66(8), 1063-1073. https://doi.org/10.1016/j. jbusres.2012.03.003

Klos, C., Spieth, P., Clauss, T., \& Klusmann, C. (2021). Digital Transformation of Incumbent Firms: A Business Model Innovation Perspective. IEEE Transactions on Engineering Management, 1-17. https://doi.org/10.1109/TEM.2021.3075502
Knight, L., \& Harland, C. (2005). Managing supply networks: organizational roles in network management. European Management Journal, 23(3), 281-292. https://doi.org/10.1016/j.emj.2005.04. 006

Kohtamäki, M., Einola, S., \& Rabetino, R. (2020). Exploring servitization through the paradox lens: Coping practices in servitization. International Journal of Production Economics, 226, 107619. https://doi.org/10.1016/j.ijpe.2020.107619

Kohtamäki, M., Parida, V., Oghazi, P., Gebauer, H., \& Baines, T. (2019). Digital servitization business models in ecosystems: A theory of the firm. Journal of Business Research, 104, 380-392. https://doi.org/10.1016/j.jbusres.2019.06.027

Koskela-Huotari, K., Edvardsson, B., Jonas, J. M., Sörhammar, D., \& Witell, L. (2016). Innovation in service ecosystems-Breaking, making, and maintaining institutionalized rules of resource integration. Journal of Business Research, 69(8), 2964-2971. https://doi.org/10.1016/j.jbusres.2016.02.029

Kreye, M. E., Goh, Y. M., Newnes, L. B., \& Goodwin, P. (2012). Approaches to displaying information to assist decisions under uncertainty. Omega, 40(6), 682-692. https://doi.org/10.1016/j. omega.2011.05.010

Kruchten, P. (2004). The rational unified process: An introduction. Addison-Wesley Professional.

Lievens, A., \& Blažević, V. (2021). A service design perspective on the stakeholder engagement journey during B2B innovation: Challenges and future research agenda. Industrial Marketing Management, 95, 128-141. https://doi.org/10.1016/j.indmarman.2021. 04.007

Lusch, R. F., \& Nambisan, S. (2015). Service innovation: A servicedominant logic perspective. MIS Quarterly, 39(1), 155-175.

Maglio, P. P., \& Lim, C. (2018). Innovation and smart service systems. Edward Elgar Publishing.

Maglio, P. P., \& Lim, C.-H. (2016). Innovation and big data in smart service systems. Journal of Innovation Management, 4(1), 11-21. https://doi.org/10.24840/2183-0606_004.001_0003

Maglio, P. P., Vargo, S. L., Caswell, N., \& Spohrer, J. (2009). The service system is the basic abstraction of service science. Information Systems and E-Business Management, 7(4), 395-406. https://doi.org/10.1007/s10257-008-0105-1

Martinez, V., Bastl, M., Kingston, J., \& Evans, S. (2010). Challenges in transforming manufacturing organisations into product-service providers. Journal of Manufacturing Technology Management, 21(4), 449-469. https://doi.org/10.1108/17410381011046571

Miller, K. D. (1992). A Framework for Integrated Risk Management in International Business. Journal of International Business Studies, 23(2), 311-331. https://doi.org/10.1057/palgrave.jibs. 8490270

National Science Foundation. (2014). Partnerships for innovation: Building innovation capacity (PFI:BIC). https://www.nsf.gov/ pubs/2013/nsf13587/nsf13587.htm

Ndubisi, N. O., Dayan, M., Yeniaras, V., \& Al-Hawari, M. (2020). The effects of complementarity of knowledge and capabilities on joint innovation capabilities and service innovation: The role of competitive intensity and demand uncertainty. Industrial Marketing Management, 89, 196-208. https://doi.org/10.1016/j.indma rman.2019.05.011

Ng, I., Parry, G., Smith, L., Maull, R., \& Briscoe, G. (2012). Transitioning from a goods-dominant to a service-dominant logic: Visualising the value proposition of Rolls-Royce. Journal of Service Management, 23(3), 416-439. https://doi.org/10.1108/ 09564231211248480.

O'Connor, G. C., \& Rice, M. P. (2013). A Comprehensive Model of Uncertainty Associated with Radical Innovation: Uncertainty and Radical Innovation. Journal of Product Innovation Management, 30(S1), 2-18. https://doi.org/10.1111/jpim.12060 
Ortiz de Guinea, A., \& Raymond, L. (2019). Improving SMEs' service innovation performance in the face of uncertainty through it ambidexterity: A configurational approach. Proceedings of the 52nd Hawaii International Conference on System Sciences (HICCS).

Osterwalder, A., Pigneur, Y., Smith, A., \& Etiemble, F. (2020). The invincible company: How to constantly reinvent your organization with inspiration from the World's best business models. John Wiley \& Sons.

Ostrom, A. L., Parasuraman, A., Bowen, D. E., Patrício, L., \& Voss, C. A. (2015). Service research priorities in a rapidly changing context. Journal of Service Research, 18(2), 127-159. https:// doi.org/10.1177/1094670515576315

Paiola, M., \& Gebauer, H. (2020). Internet of things technologies, digital servitization and business model innovation in BtoB manufacturing firms. Industrial Marketing Management, 89, 245-264. https://doi.org/10.1016/j.indmarman.2020.03.009

Paluch, S., \& Tuzovic, S. (2019). Persuaded self-tracking with wearable technology: Carrot or stick? Journal of Services Marketing, 33(4), 436-448. https://doi.org/10.1108/JSM-03-2018-0091

Papert, M., \& Pflaum, A. (2017). Development of an Ecosystem Model for the Realization of Internet of Things (IoT) Services in Supply Chain Management. Electronic Markets, 31(3), 306. https://doi. org/10.1007/s12525-017-0251-8

Parida, V., Sjödin, D., \& Reim, W. (2019). Reviewing literature on digitalization, business model innovation, and sustainable industry: Past achievements and future promises. Sustainability, 11(2), 391. https://doi.org/10.3390/su11020391

Paschou, T., Rapaccini, M., Adrodegari, F., \& Saccani, N. (2020). Digital servitization in manufacturing: A systematic literature review and research agenda. Industrial Marketing Management, 89, 278-292. https://doi.org/10.1016/j.indmarman.2020.02.012

Plattfaut, R., Niehaves, B., Voigt, M., Malsbender, A., Ortbach, K., \& Poeppelbuss, J. (2015). Service innovation performance and information technology: An empirical analysis from the dynamic capability perspective. International Journal of Innovation Management, 19(04), 1550038.

PMI. (2020). Foundation for Business Agility I Disciplined Agile. https://www.pmi.org/disciplined-agile

PwC. (2019). Digital Auto Report. PwC. https://www.strategyand.pwc. $\mathrm{com} / \mathrm{de} / \mathrm{en} /$ industries/automotive/digital- auto-report.html

Rabe, M., Kühn, A., Dumitrescu, R., Mittag, T., Schneider, M., \& Gausemeier, J. (2018). Impact of smart services to current value networks. Journal of Mechanical Engineering, 5(4), $1-11$.

Ramirez Hernandez, T., \& Kreye, M. E. (2021). Uncertainty profiles in engineering-service development: Exploring supplier co-creation. Journal of Service Management, 32(3), 407-437. https://doi.org/10.1108/JOSM-08-2019-0270

Rehn, A., \& Lindahl, M. (2012). Muddling through in innovationOn incremental failure in developing an engine. Journal of Business Research, 65(6), 807-813. https://doi.org/10.1016/j. jbusres.2010.12.020

Riasanow, T., Jäntgen, L., Hermes, S., Böhm, M., \& Krcmar, H. (2021). Core, intertwined, and ecosystem- specific clusters in platform ecosystems: Analyzing similarities in the digital transformation of the automotive, blockchain, financial, insurance and IIoT industry. Electronic Markets, 31(1), 89-104. https://doi.org/10.1007/s12525-020-00407-6

Richter, F., \& Anke, J. (2021). Combining methods for the design of digital services in practice: experiences from a predictive costing service. 16th International Conference on Wirtschaftsinformatik (WI 2021), Essen, Germany.

Scaled Agile Inc. (2020). SAFe 5.0 Framework. Scaled Agile Framework. https://www.scaledagileframework.com/
Schymanietz, M., \& Jonas, J. M. (2020). The roles of individual actors in data-driven service innovation - a dynamic capabilities perspective to explore its microfoundations. Proceedings of the 53rd Hawaii International Conference on System Sciences (HICCS). https://doi.org/10.24251/HICSS.2020.142

Simangunsong, E., Hendry, L. C., \& Stevenson, M. (2012). Supplychain uncertainty: A review and theoretical foundation for future research. International Journal of Production Research, 50(16), 4493-4523. https://doi.org/10.1080/00207543.2011. 613864

Sjödin, D., Parida, V., Jovanovic, M., \& Visnjic, I. (2020a). Value creation and value capture alignment in business model innovation: A process view on outcome-based business models. Journal of Product Innovation Management, 37(2), 158-183. https://doi.org/10.1111/jpim.12516

Sjödin, D., Parida, V., Kohtamäki, M., \& Wincent, J. (2020b). An agile co-creation process for digital servitization: A microservice innovation approach. Journal of Business Research, 112, 478-491. https://doi.org/10.1016/j.jbusres.2020.01.009

Sklyar, A., Kowalkowski, C., Tronvoll, B., \& Sörhammar, D. (2019). Organizing for digital servitization: A service ecosystem perspective. Journal of Business Research, 104, 450-460. https:// doi.org/10.1016/j.jbusres.2019.02.012

Sniazhko, S. (2019). Uncertainty in decision-making: A review of the international business literature. Cogent Business \& Management, 6(1), 1650692. https://doi.org/10.1080/23311975. 2019.1650692

Spohrer, J., Anderson, L. C., Pass, N. J., Ager, T., \& Gruhl, D. (2008). Service Science. Journal of Grid Computing, 6(3), 313-324. https://doi.org/10.1007/s10723-007-9096-2

Storbacka, K. (2019). Actor engagement, value creation and market innovation. Industrial Marketing Management, 80, 4-10. https://doi.org/10.1016/j.indmarman.2019.04.007

Storbacka, K., Brodie, R. J., Böhmann, T., Maglio, P. P., \& Nenonen, S. (2016). Actor engagement as a microfoundation for value co-creation. Journal of Business Research, 69(8), 3008-3017. https://doi.org/10.1016/j.jbusres.2016.02.034

Story, V., O’Malley, L., \& Hart, S. (2011). Roles, role performance, and radical innovation competences. Industrial Marketing Management, 40(6), 952-966. https://doi.org/10.1016/j.indma rman.2011.06.025

Teece, D. J. (2007). Explicating dynamic capabilities: The nature and microfoundations of (sustainable) enterprise performance. Strategic Management Journal, 28(13), 1319-1350. https://doi. org/10.1002/smj.640

Usländer, T., \& Batz, T. (2018). Agile Service Engineering in the Industrial Internet of Things. Future Internet, 10(10), 100 https://doi.org/10.3390/fi10100100

van Riel, A. C. R., Lemmink, J., \& Ouwersloot, H. (2004). HighTechnology Service Innovation Success: A Decision-Making Perspective. Journal of Product Innovation Management, 21(5), 348-359. https://doi.org/10.1111/j.0737-6782.2004. 00087.x

Vargo, S. L., \& Akaka, M. A. (2012). Value Cocreation and Service Systems (Re)Formation: A Service Ecosystems View. Service Science, 4(3), 207-217. https://doi.org/10.1287/serv.1120.0019

Vargo, S. L., \& Lusch, R. F. (2011). It's all B2B... and beyond: Toward a systems perspective of the market. Industrial Marketing Management, 40(2), 181-187. https://doi.org/10.1016/j. indmarman.2010.06.026

Vargo, S. L., \& Lusch, R. F. (2016). Institutions and axioms: An extension and update of service-dominant logic. Journal of the Academy of Marketing Science, 44(1), 5-23. https://doi.org/10. 1007/s11747-015-0456-3 
Vargo, S. L., \& Lusch, R. F. (2017). Service-dominant logic 2025. International Journal of Research in Marketing, 34(1), 46-67. https://doi.org/10.1016/j.ijresmar.2016.11.001

Vargo, S. L., Lusch, R. F., Archpru Akaka, M., \& He, Y. (2010). Service-dominant logic. In N. K. Malhotra (Ed.), Review of Marketing Research, 6, 125-167. Emerald Group Publishing Limited. https://doi.org/10.1108/S1548-6435(2009)00000 06010

Vial, G. (2019). Understanding digital transformation: A review and a research agenda. The Journal of Strategic Information Systems, 28(2), 118-144. https://doi.org/10.1016/j.jsis.2019. 01.003

Vink, J., Koskela-Huotari, K., Tronvoll, B., Edvardsson, B., \& Wetter-Edman, K. (2021). Service ecosystem design: Propositions, process model, and future research agenda. Journal of Service Research, 24(2), 168-186. https://doi.org/10.1177/1094670520 952537

Warner, K. S. R., \& Wäger, M. (2019). Building dynamic capabilities for digital transformation: An ongoing process of strategic renewal. Long Range Planning, 52(3), 326-349. https://doi. org/10.1016/j.lrp.2018.12.001

Weking, J., Stöcker, M., Kowalkiewicz, M., Böhm, M., \& Krcmar, H. (2020). Leveraging industry 4.0 - A business model pattern framework. International Journal of Production Economics, 225, 107588. https://doi.org/10.1016/j.ijpe.2019.107588

Wessel, L., Baiyere, A., Ologeanu-Taddei, R., Cha, J., \& Jensen, T. B. (2020). Unpacking the difference between digital transformation and IT-enabled organizational transformation. Journal of Association of Information Systems, 22(1). https://doi.org/ 10.17705/1jais.00655

Wiesböck, F., \& Hess, T. (2020). Digital innovations. Electronic Markets, 30(1), 75-86. https://doi.org/10.1007/ s12525-019-00364-9
Wolf, V., Bartelheimer, C., \& Beverungen, D. (2020). Establishing smart service systems is a challenge: A case study on pitfalls and implications. 15th International Conference on Wirtschaftsinformatik (WI 2020), Potsdam, Germany. https://doi.org/10. 30844/wi_2020_t4-wolf

Wünderlich, N. V., Heinonen, K., Ostrom, A. L., Patricio, L., Sousa, R., Voss, C., \& Lemmink, J. G. A. M. (2015). "Futurizing" smart service: Implications for service researchers and managers. Journal of Services Marketing, 26(6/7) 442-44. https://doi. org/10.1108/JSM-01-2015-0040

Wünderlich, N. V., Wangenheim, F. v., \& Bitner, M. J. (2013). High tech and high touch: A framework for understanding user attitudes and behaviors related to smart interactive services. Journal of Service Research, 16(1), 3-20. https://doi.org/10.1177/ 1094670512448413

Yang, Y.-C., Ying, H., Jin, Y., Cheng, H., \& Liang, T.-P. (2021). Special issue editorial: Information systems research in the age of smart services. Journal of the Association for Information Systems, 22(3). https://doi.org/10.17705/1jais.00673

Yin, R. K. (2016). Qualitative research from start to finish. The Guilford Press, New York.

Zolnowski, A., Anke, J., \& Gudat, J. (2017). Towards a cost-benefit-analysis of data-driven business models. 13th International Conference on Wirtschaftsinformatik (WI 2017), St. Gallen, Switzerland.

Publisher's note Springer Nature remains neutral with regard to jurisdictional claims in published maps and institutional affiliations. 